\title{
THE
}

$9-15-2000$

\section{Durophagy in Sharks: Feeding Mechanics of the Hammerhead Sphyrna tiburo}

Cheryl D. Wilga

University of Rhode Island, cwilga@uri.edu

Philip J. Motta

Follow this and additional works at: https://digitalcommons.uri.edu/bio_facpubs

Creative Commons License

\section{(c) (i) (9)}

This work is licensed under a Creative Commons Attribution-Noncommercial 3.0 License

\section{Citation/Publisher Attribution}

Wilga, C.D. and P.J. Motta. 2000. Durophagy in sharks: feeding mechanics of hammerhead sharks, Sphyrna tiburo. Journal of Experimental Biology, 203: 2781-2796.

Available at: http://jeb.biologists.org/content/203/18/2781

JEB2810

This Article is brought to you for free and open access by the Biological Sciences at DigitalCommons@URI. It has been accepted for inclusion in Biological Sciences Faculty Publications by an authorized administrator of DigitalCommons@URI.For more information, please contact digitalcommons-group@uri.edu. 


\title{
DUROPHAGY IN SHARKS: FEEDING MECHANICS OF THE HAMMERHEAD SPHYRNA TIBURO
}

\author{
CHERYL D. WILGA* AND PHILIP J. MOTTA \\ Department of Biology, University of South Florida, Tampa, FL 33620, USA \\ *Present address: Museum of Comparative Zoology, Harvard University, 26 Oxford Street, Cambridge, MA 02138, USA \\ (e-mail: cwilga@oeb.harvard.edu)
}

Accepted 20 June; published on WWW 22 August 2000

\begin{abstract}
Summary
This study investigates the motor pattern and head movements during feeding of a durophagus shark, the bonnethead Sphyrna tiburo, using electromyography and simultaneous high-speed video. Sphyrna tiburo feeds almost exclusively on hard-shelled crabs, with shrimp and fish taken occasionally. It captures crabs by ram feeding, then processes or reduces the prey by crushing it between molariform teeth, finally transporting the prey by suction for swallowing. The prey-crushing mechanism is distinct from that of ram or bite capture and suction transport. This crushing mechanism is accomplished by altering the duration of jaw adductor muscle activity and modifying jaw kinematics by the addition of a second jaw-closing phase. In crushing events, motor activity of the jaw

transport events during which motor activity (biting) ceases at jaw closure. Sphyrna tiburo is able to take advantage of a resource (hard prey) that is not readily available to most sharks by utilizing a suite of durophagous characteristics: molariform teeth, a modified jaw protrusor muscle, altered jaw adductor activity and modified jaw kinematics. Sphyrna tiburo is a specialist feeder on crab prey as demonstrated by the lack of differences in kinematic or motor patterns when offered prey of differing hardness and its apparent lack of ability to modulate its behavior when feeding on other prey. Functional patterns are altered and coupled with modifications in dental and jaw morphology to produce diverse crushing behaviors in elasmobranchs.
\end{abstract} adductor muscles continues (biting of the prey occurs as the jaws close and continues after the jaws have closed) throughout a second jaw-closing phase, unlike capture and
Key words: durophagy, feeding, mechanics, hammerhead shark, capture, ram feeding, prey transport, crushing, Sphyrna tiburo.

\section{Introduction}

Crushing of hard prey by the oral jaws during feeding has been observed in only a few osteichthyan groups, such as the Sparidae, Tetraodontidae and Cichlidae (Christiansen, 1978; Liem, 1979, 1980; Barel, 1983; Buxton, 1984; Buxton and Clark, 1989, 1991; Sedberry, 1987, 1989; Vandewalle et al., 1995; Turingan and Wainwright, 1993; Wainwright and Turingan, 1993; Turingan, 1994; Hernandez and Motta, 1994). Similarly, durophagy (feeding on hard prey) in chondrichthyans has only been observed in horn sharks (Heterodontidae), some rays (Myliobatidae) and chimeras (Holocephali) (Dean, 1906; Daniel, 1922; Smith, 1942; Bigelow and Schroeder, 1953; Moss, 1972; Compagno, 1988; Motta and Wilga, 2000) (Fig. 1). These studies have found a suite of morphological characteristics related to durophagy, which include stout flattened teeth, hypertrophied jaw adductor muscles and robust jaws.

Crushing and grinding teeth are typically associated with sharks and rays that feed on hard prey, such as crustaceans and molluscs (Cappetta, 1987) (Fig. 2). We define crushing as the forceful occlusion of the opposing dental surfaces and grinding so that the dental surfaces not only oppose each other, as in crushing, but also slide past one another. Sharks that crush prey have teeth that have low cusps or that are molariform. The cusped teeth are relatively small and have low rounded cusps, there are numerous teeth per row, with the teeth occurring in numerous rows and together producing a bumpy surface. Smoothhound sharks, genus Mustelus, have low rounded cusped teeth and feed on crustaceans (Russo, 1975; Talent, 1982; Compagno, 1984; Rountree and Able, 1996). The molariform teeth are smoothly rounded and lack cusps, and there are numerous teeth per row, with the teeth occurring in numerous rows and again forming a bumpy surface. Horn sharks (Heterodontiformes) and bonnethead sharks (Sphyrna tiburo, Sphyrnidae) have molariform teeth; the anterior teeth are cuspidate and used for grasping, and the posterior teeth are molariform and used for crushing. Horn sharks feed primarily on limpets, bivalve molluscs and blue crabs, while bonnethead sharks feed almost exclusively on crabs (Garman, 1913; Smith, 1942; Segura-Zarzosa, 1997; Cortes et al., 1996; Lessa and Almeida, 1998). Chimeras (Holocephali) and some myliobatid rays have pavement teeth (Daniel, 1922; Compagno, 1988; Tricas, 1997) that are flat, usually hexagonal in shape and 


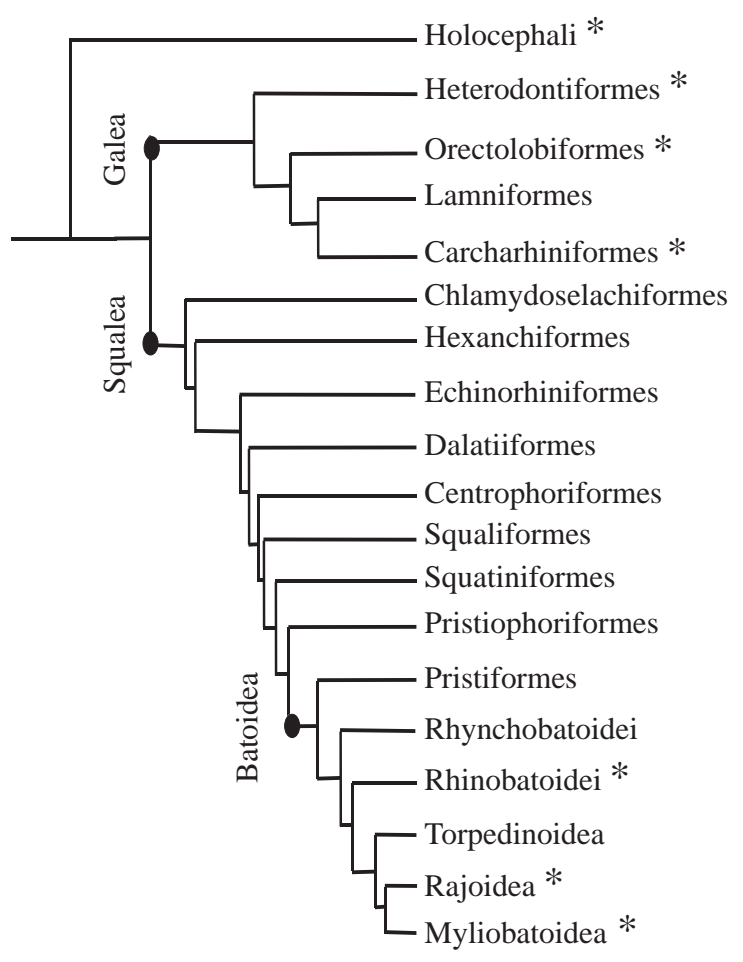

Fig. 1. Chondrichthyan cladogram showing groups (marked by asterisks) in which durophagy (consumption of hard prey) is known. Holocephali, Callorhinchus, Neoharriotta, Harriota, Rhinochimaera, Chimaera, Hydrolagus; Heterodontiformes, Heterodontus; Orectolobiformes, Ginglymostoma; Carchariniformes, Mustelus, Sphyrna tiburo; Rhinobatoidei, Rhinobatos; Rajoidea, Raja; Myliobatoidea, Aetobatus, Aetomylaeus, Myliobatis, Pteromylaeus, Rhinoptera. Compiled from Dean (1906), Daniel (1922), Smith (1942), Bigelow and Schroeder (1953), Moss (1972), Compagno (1988), Ebert et al. (1991), Shirai (1996) and Summers (2000).

interconnect to form an even dental plate. Durophagus myliobatids, such as cownose (genus Rhinoptera) and eagle (genera Myliobatis and Aetobatus) rays and chimeras use their pavement teeth for grinding molluscs, gastropods and crabs (Daniel, 1922; Bigelow and Schroeder, 1953; Talent, 1982; Russell, 1983; Compagno, 1984; Cappetta, 1987; Di Giancomo and Perier, 1996; Gray et al., 1997). Some skates and guitarfish, such as Rhinobatos spp. (Talent, 1982; Wilga and Motta, 1998b), also have low rounded cusped teeth and crush or grind their prey.

A recent morphological study of durophagus myliobatid stingrays identified several morphological characteristics enabling these fishes to grind hard prey: flat, pavement-like tooth plates, calcified strengthened cartilaginous jaws, calcified struts within the jaws and a lever system that amplifies the force of the jaw adductor muscles (Summers, 2000). Furthermore, fusion of the palatoquadrate and mandibular symphyses, a restricted gape and asynchronous activation of the jaw adductors are key elements in a proposed 'nutcracker' model of jaw-crushing ability. A similar biomechanical study of crushing in horn sharks, Heterodontus philippi, proposed
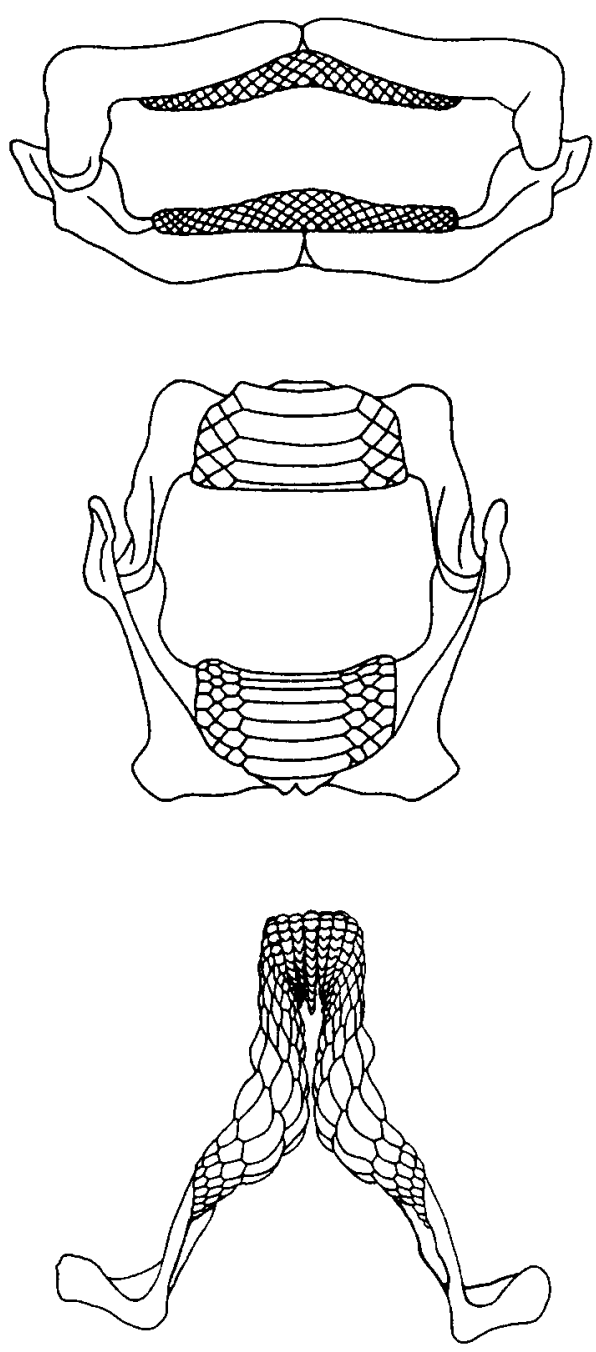

Fig. 2. Selected dental types in elasmobranchs. Crushing type represented by Raja (top), grinding by Myliobatis (middle) and clutching-grinding by Heterodontus (lower jaw only) (bottom) (after Cappetta, 1987).

that the line of action of the hypertrophied adductor muscles generates the strongest force in the region of the largest molariform teeth, with force decreasing towards the jaw joint and symphyses (Nobiling, 1977). These hypotheses have yet to be tested in live feeding fishes.

The mechanism of prey crushing in the oral jaws has been extensively studied only in queen triggerfish, Balistes vetula (Turingan and Wainwright, 1993; Wainwright and Turingan, 1993). Activity in the jaw adductor muscles lasted longer when feeding on hard prey compared with soft prey (Wainwright and Turingan, 1993). In addition, the motor patterns during bite capture and prey processing of crab were indistinguishable from each other, with both of these behaviors being different from that of suction capture (Turingan and Wainwright, 1993). Triggerfish specializations for durophagy include the loss of jaw protrusion ability, a tighter upper jaw/cranial connection, enlarged jaw adductor muscles and stout teeth (Turingan and 
Wainwright, 1993; Wainwright and Turingan, 1993). The mechanism of prey-crushing behavior in a chondrichthyan has yet to be investigated functionally.

In this study, we investigate the feeding behavior of a shark that has a morphological characteristic related to durophagy possessed by few sharks, molariform teeth, and that specializes in feeding on hard-shelled crustaceans (crabs). We examine the kinematics and motor pattern of prey capture, processing and transport behaviors in bonnethead sharks Sphyrna tiburo (Carcharhiniformes) with crab as hard prey, shrimp as intermediate prey and fish as soft prey using high-speed video and electromyography. In this study, we ask several questions related to durophagous feeding mechanisms. (i) What morphological characteristics of durophagy does Sphyrna tiburo possess that non-durophagous sharks lack? (ii) Does $S$. tiburo alter motor or kinematic patterns among capture, manipulation and transport (feeding behaviors)? (iii) Does $S$. tiburo alter motor or kinematic patterns in response to prey hardness? Finally, the crushing mechanism of S. tiburo is compared with that of other fishes to investigate common functional solutions to the problems of consuming hard prey.

\section{Materials and methods \\ Research specimens}

Three Sphyrna tiburo L. individuals $(56.5,59.0$ and $66.5 \mathrm{~cm}$ total length, $T L$ ) were collected by gill net from the Gulf of Mexico off Longboat Key, Sarasota, Florida, USA, and held in a $5 \mathrm{~m}$ diameter circular holding tank with continuous fresh flowing sea water. Sharks were fed three times a week with the following natural prey items (Cortes et al., 1996), speckled crab (Arenaeus cribrarius), pink shrimp (Penaeus duorarum) and Atlantic thread herring (Opisthonema oglium). A few days prior to the experiment, the shark was transferred to a 14001 semicircular experimental tank that was also provided with continuous fresh flowing sea water.

\section{Morphology}

The skeletal elements and muscles of the head and hypobranchial region of five fresh dead specimens $(50-96.6 \mathrm{~cm}$ $T L$ ) were dissected and described to ensure consistent electrode placement. Muscles that have been previously shown or suspected to function during feeding (epaxialis, coracomandibularis, levator palatoquadrati, levator hyomandibularis, quadratomandibularis and preorbitalis) were implanted with electrodes (Moss, 1972, 1977; Frazzetta, 1994; Motta et al., 1997; Motta and Wilga, 1995).

\section{High-speed video recording and analysis}

A NAC HSV-200 high-speed video system at 200 fields s ${ }^{-1}$ was used to film the sharks during feeding experiments. Two cameras were used to film the lateral and ventral views simultaneously. Head and jaw kinematics of three individuals while feeding were analyzed using high-speed video. Sequential video fields of selected feeding events were downloaded with a Creative Labs Video Blaster capture board and a Panasonic (model AG-1970) video recorder. Cranial movements were then digitized from video images recorded during four capture, process and transport events from each of three individuals for a total of 36 events. The following landmarks were digitized from $-50 \mathrm{~ms}$ prior to lower jaw depression until the end of jaw retraction (approximately 35 digitized fields per event): the tip of the lower jaw, the tip of the snout, the tip of the upper jaw, the hyoid region ventral to the corner of the mouth, the hypobranchial point ventral to the first gill slit, the eye at the anterior end, the dorsal surface of the head above the first gill slit and the point on the prey item most distal from the shark.

\section{Electromyography and analysis}

Electromyographic (EMG) recordings were taken simultaneously with video recordings to document the sequence of muscle activation relative to kinematic pattern. Bipolar electrodes constructed from $1.8 \mathrm{~m}$ lengths of $0.0057 \mathrm{~cm}$ diameter insulated alloy wire (Carpenter Technology Corp.) were used to record muscle activity. One millimeter at the tip of each wire was stripped of insulation and bent backwards to form a hook. Another $3 \mathrm{~cm}$ long piece of hooked insulated wire was placed behind each bipolar electrode to verify the position of electrode insertion in case the electrode was inadvertently pulled out. Electrodes were implanted with 26 gauge hypodermic needles into six cranial muscles: coracomandibularis, epaxialis, levator hyomandibularis, levator palatoquadrati, ventral preorbitalis and dorsal quadratomandibularis. The number of muscles implanted was kept to a minimum because of the sensitive nature of this species to invasive surgery. The shark was anesthetized for surgery using $0.06 \mathrm{gl}^{-1}$ tricaine methanesulfonate (MS 222). The shark was intubated and maintained on this dosage of anesthetic during surgery using a recirculating pump. After the electrodes had been implanted, they were glued together and sutured to the skin anterior to the first dorsal fin. The surgical procedure took approximately $20 \mathrm{~min}$. The shark was returned to the experimental tank and intubated, and fresh sea water was circulated until it had recovered enough to commence swimming (5-15 min). Feeding trials were initiated after normal swimming behavior had been observed for at least $3 \mathrm{~h}$ post-recovery and continued until the shark was satiated. Prey items consisted of whole speckled crab Arenaeus cribrarius (dead, carapace width approximately $5 \mathrm{~cm}$ ), whole pink shrimp Penaeus duorarum (dead, length approximately $6 \mathrm{~cm}$ ) or Atlantic thread herring Opisthonema oglium pieces $(4 \mathrm{~cm} \times 2 \mathrm{~cm})$. Crabs have a relatively hard robust shell, shrimp have a softer shell and fish were the softest prey item.

Electrode wires from the shark were attached to a multi-pin connector in turn connected to $3 \mathrm{~m}$ low-noise cables attached to AM Systems (model 1700) a.c. differential amplifiers at a gain of 1000 , bandpass $100-3000 \mathrm{~Hz}$ with $60 \mathrm{~Hz}$ notch filter. All six cranial muscles were recorded simultaneously. Electromyographic signals were simultaneously monitored on a Tektronix (model 2214) four-channel oscilloscope and recorded using a Western Graphtec (model Mark-11) eight- 


\section{C. D. Wilga And P. J. MotTA}

channel thermal array recorder. Signals were multiplexed using a Vetter (model 3000A) pulse code modulator and recorded onto a TEAC (model MV 520) cassette recorder. A synchronizer unit was used to synchronize the EMG and video recordings, which emitted a programmed variable pulsed pattern that was recorded onto one channel of the tape recorder and by one video camera.

At the termination of each experiment, the shark was killed with an overdose of MS-222 according to the University of South Florida and Mote Marine Laboratory Institutional Animal Care and Use Committee Guidelines. The positions of the electrodes were verified by dissection, and total length was measured to the nearest millimeter.

Motor activity patterns of selected head muscles were recorded during simultaneous high-speed video during feeding in $S$. tiburo $(56.5,59$ and $66.5 \mathrm{~cm} \mathrm{TL}$ ). Analog EMG data for individual feeding events were digitized using a Cambridge Electronics Design (model 1401 plus) analog-to-digital converter controlled by Spike 2 software and a customdesigned EMG analysis program. For the electromyographic analysis, four capture, process and transport events from each of three individuals were analyzed, giving a total of 36 events. Motor patterns were analyzed for burst duration and onset relative to the quadratomandibularis muscle (reference muscle).

\section{Statistical analyses}

Motor patterns and kinematic variables from capture, processing and transport data were analyzed using a mixedmodel two-way analysis of variance (ANOVA) using type III sums of squares. Individual is a random main effect, and behavior is a fixed main effect tested by the individual $x$ behavior term. Variables tested included the onset and duration of EMG activity and the start, peak, end, duration and magnitude of kinematic activity. If a difference was detected by ANOVA, a Student-Newman-Keuls multiple-comparison test was applied. Statistical tests were calculated using SAS (version 6.12). Motor patterns and kinematic variables from crab, shrimp and fish feeding data were analyzed using Kruskal-Wallis one-way ANOVA on ranks. The data were tested for homogeneous variances using the Levene median test and for normal distribution using the KolmogorovSmirnov test using SigmaStat (SPSS Software version 2.0). If the data did not meet these assumptions of parametric statistics, they were log-transformed, after which the assumptions were satisfied.

\section{Results \\ Jaw suspension}

Sphyrna tiburo has a hyostylic type of jaw suspension in which the hyomandibula suspends the jaws from the cranium, the palatoquadrate or upper jaw articulates with the cranium through an orbital process and ethmopalatine ligament, and the ceratohyal-basihyal complex articulates with the hyomandibula (Fig. 3). The palatoquadrate and Meckel's
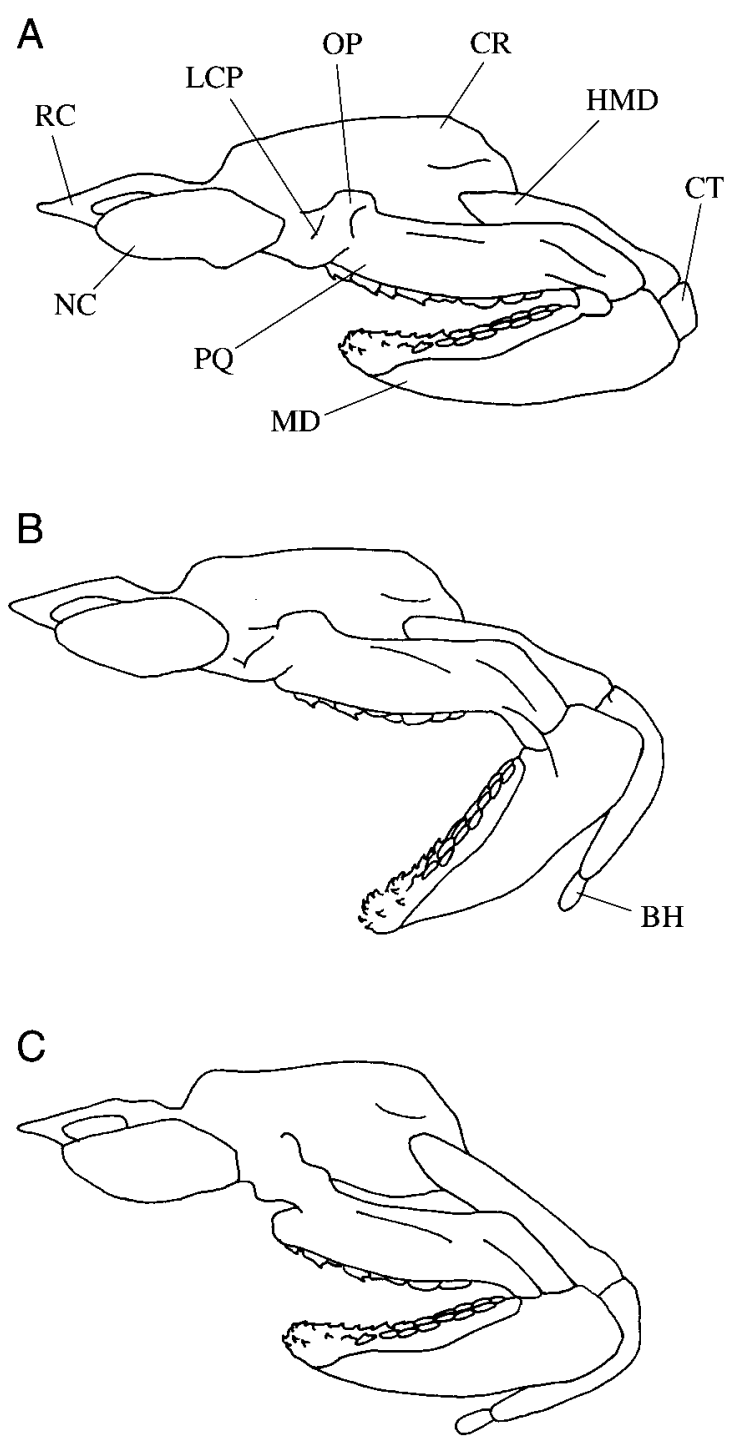

Fig. 3. Left lateral view of the cranium, jaws and hyoid arch of an $84 \mathrm{~cm}$ total length female Sphyrna tiburo with the skin and muscles removed. (A) In the retracted state, the jaws and hyoid lie under the cranium and the orbital process lies in the ethmopalatine groove. (B) At peak lower jaw depression, the lower jaw and hyoid are depressed posteroventrally away from the cranium. (C) At peak upper jaw protrusion, the upper jaw is protruded ventroposteriorly away from the cranium, the orbital process has cleared the ethmopalatine groove up to the length of the ethmopalatine ligament and the hyomandibula has been depressed anteroventrally away from the cranium. $\mathrm{BH}$, basihyal; $\mathrm{CT}$, ceratohyal; $\mathrm{CR}$, cranium; HMD, hyomandibula; LCP, ethmopalatine ligament; MD, mandible; NC, nasal capsule; OP, orbital process; $\mathrm{PQ}$, palatoquadrate; $\mathrm{RC}$, rostrum.

cartilage (lower jaw) are oriented anteriorly. The symphysis between the two halves of the palatoquadrate and Meckel's cartilage is tight, but not fused, and allows little movement between the two halves. In the resting position, the short orbital process of the upper jaw lies in a vertically oriented ethmopalatine groove in the orbital wall. A relatively thick ethmopalatine ligament extends from the edges of the 


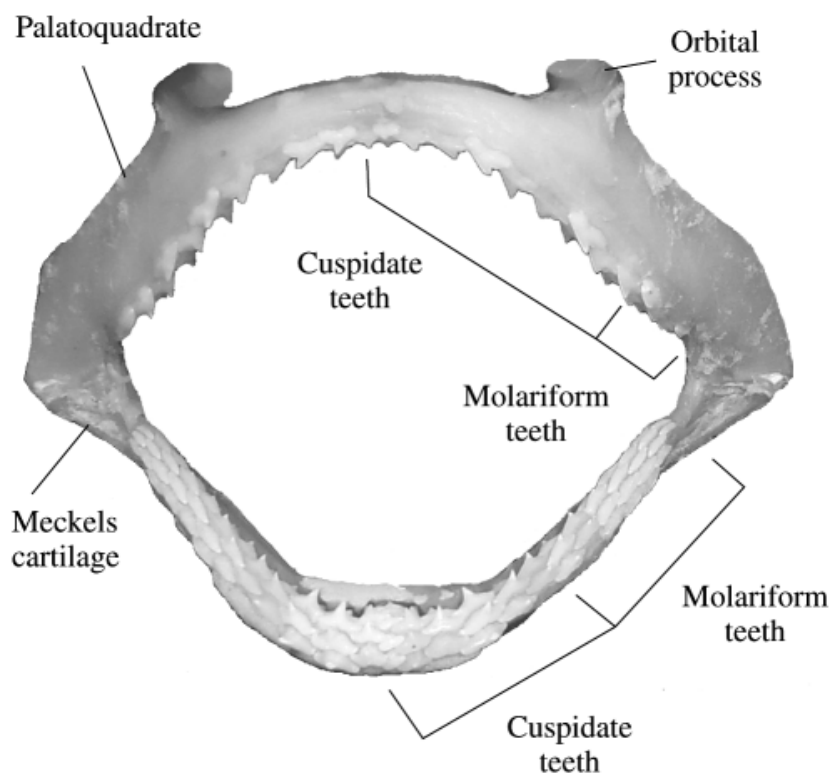

Fig. 4. The dentition of Sphyrna tiburo ( $84 \mathrm{~cm} \mathrm{TL).} \mathrm{Note} \mathrm{the} \mathrm{cutting-}$ type teeth in the anterior region of the jaws and the elongated molariform teeth in the posterior region of the jaws.

ethmopalatine groove to the orbital process. In the retracted position, the ethmopalatine ligament folds back on itself. Anteroposterior movement of the retracted upper jaw is restricted by the orbital process in the ethmopalatine groove, the ectethmoid condyles and the hyomandibula. The orbital process just clears the ethmopalatine groove at peak upper jaw protrusion. Ventral movement of the upper jaw is permitted up to the length of the unfolded ethmopalatine ligament and skin between the upper jaw and chondrocranium. The anterior teeth are a grasping cuspidate type, while the posterior teeth are molariform (Fig. 4).

\section{Myology}

Six of the major muscles that have previously been shown or suspected to function during feeding were implanted: the epaxialis, coracomandibularis, dorsal quadratomandibularis, ventral preorbitalis, levator palatoquadrati and levator hyomandibularis (Fig. 5). The anatomy of all the cranial muscles is described for clarity. The levator palatoquadrati muscle originates on the anterodorsal chondrocranium and orbital wall and extends posteroventrally to insert on the mid-dorsal surface of the palatoquadrate. The levator hyomandibularis muscle originates on the dorsolateral edge of the epaxialis from its anterior edge to the first branchial constrictor and inserts on the dorsal surface of the hyomandibula. The dorsal preorbitalis muscle originates on the mid-lateral raphe of the quadratomandibularis and extends anterodorsally to insert on the dorsolateral edge of the palatoquadrate from the orbital process to the margin of the dorsal quadratomandibularis muscle. The mid-lateral raphe is a thin connective tissue that separates the dorsal and ventral divisions of the quadratomandibularis muscle (shown as a
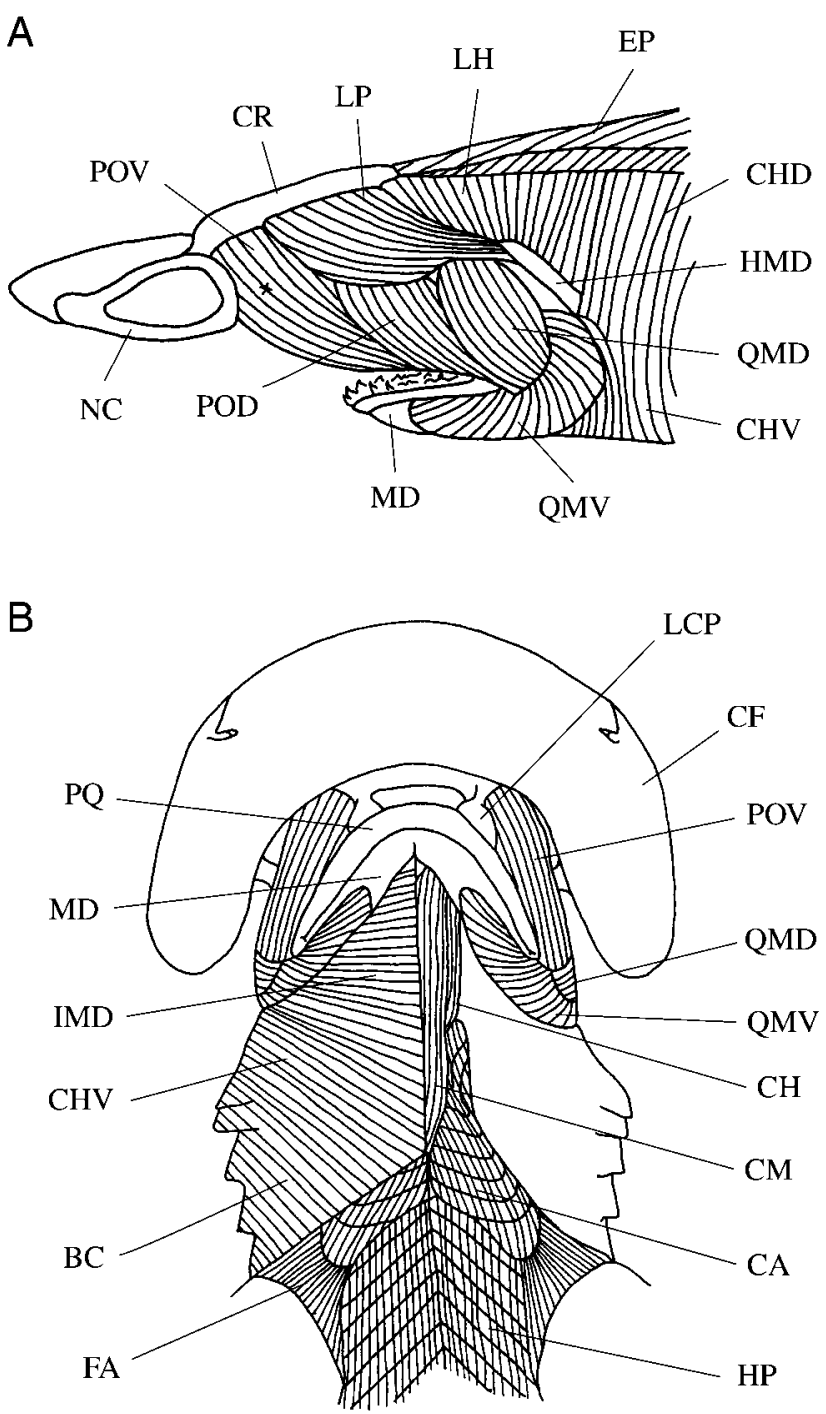

Fig. 5. Left lateral (A) and ventral (B) views of the head of a $96.6 \mathrm{~cm}$ total length female Sphyrna tiburo with the skin removed over the muscles and muscle fiber direction indicated. Only the myosepta of the epaxialis muscle are indicated. In A, the left lateral cephalic lobe was removed, with $\mathrm{x}$ indicating the approximate position of the eye. $\mathrm{BC}$, branchial constrictors; CA, coracoarcualis; CF, cephalofoil; $\mathrm{CH}$, coracohyoideus; $\mathrm{CHD}$, constrictor hyoideus dorsalis; $\mathrm{CHV}$, constrictor hyoideus ventralis; CM, coracomandibularis; CR, cranium; EP, epaxialis; FA, fin adductor; HMD, hyomandibula; HP, hypaxialis; IMD, intermandibularis; LCP, ethmopalatine ligament; LH, levator hyomandibularis; LP, levator palatoquadrati; MD, mandible or lower jaw; NC, nasal capsule; POD, dorsal preorbitalis; POV, ventral preorbitalis; PQ, palatoquadrate or upper jaw; QMD, dorsal quadratomandibularis; QMV, ventral quadratomandibularis.

horizontal line between the dorsal and ventral divisions of the quadratomandibularis). The ventral preorbitalis muscle originates on the nasal capsule and orbital wall and extends posterolaterally to merge with the dorsal preorbitalis muscle at its ventral edge and inserts on the mid-lateral raphe at the corner of the mandible. The dorsal quadratomandibularis muscle originates on the mid-lateral raphe and extends dorsally 
to insert on the dorsal surface of the palatoquadrate. The ventral quadratomandibularis muscle originates on the midlateral raphe and fans out anteroventrally to posteroventrally to insert on the lateral surface of the mandible. The coracomandibularis muscle originates on the coracoid bar and pericardium and extends anteriorly to insert on the posterior surface of the mandible on either side of the symphysis. The coracohyoideus muscle originates on the anteroventral surface of the coracoarcualis muscle and extends anteriorly to insert on the basihyal. The coracoarcualis muscle originates on the anterior surface of the coracoid bar and the ventral surface of the fin adductor and extends anteriorly to insert on the posterodorsal surface of the coracohyoideus. The epaxialis muscle extends anteriorly to insert on the posterior surface of the otic capsule of the chondrocranium dorsal to the vertebral column. The hypaxialis muscle extends anteriorly ventral to the vertebral column and inserts on the posterior half of the basal plate (posterior ventral region) of the cranium. The intermandibularis muscle originates on the mid-ventral raphe (shown as line at the medial edge of the muscle) and extends anterolaterally to insert on the ventral edges of the mandible and the ventral quadratomandibularis muscle. The interhyoideus muscle (not illustrated) is deep to the intermandibularis muscle and originates on the mid-ventral raphe and extends laterally to insert on the ventromedial edges of the ceratohyal cartilage.

\section{Kinematics}

Several feeding behaviors were observed by $S$. tiburo that can be placed into five major categories: capture or initial acquisition of prey, manipulation or repositioning of prey within the jaws, processing or reducing prey integrity, transport or movement of prey from the oral jaws to the esophagus, and swallowing or movement of prey through the esophagus. In this paper, we focus on three behaviors (capture, processing and transport) and three prey types (crab, shrimp and fish).

Sphyrna tiburo typically captures prey using a ram mechanism, in which the predator approaches the prey with the mouth wide open and engulfs it (Fig. 6). After capture of the prey, several manipulation or processing events are usually performed on the prey to reposition and reduce it prior to swallowing. Processing in S. tiburo may consist of any combination of lateral headshakes and crushing of the prey. Shaking of crab prey by $S$. tiburo often resulted in the clawed legs being severed from the carapace. Only processing events in which the jaws were opened and closed again onto the prey, such as for crushing hard prey, were chosen for analysis in this study. Occasionally, Sphyrna tiburo individuals over-swam the prey. When this occurred, the head was bent down at a large angle, and the cephalofoil was used to immobilize the prey against the substratum before proceeding to capture it. Transport of the prey from the jaws to the esophagus is by suction and is the last event that we analyzed. The prey clearly moves from the buccal cavity towards the pharyngeal region faster than the forward movement of the swimming shark. During transport, the shark does not move forward very much
Table 1. Statistical variables and results of ANOVA on timing variables during ram capture, crush processing and suction transport events in Sphyrna tiburo

\begin{tabular}{lrrrrr}
\hline $\begin{array}{l}\text { Kinematic } \\
\text { variable }\end{array}$ & Capture & Process & Transport & $P$-value & SNK \\
\hline HL start & $-2 \pm 60$ & $18 \pm 28$ & $-17 \pm 43$ & 0.2535 & \\
HL duration & $46 \pm 20$ & $62 \pm 13$ & $78 \pm 38$ & 0.0055 & \\
HL peak & $44 \pm 34$ & $62 \pm 16$ & $66 \pm 18$ & 0.5560 & \\
HD duration & $127 \pm 58$ & $95 \pm 27$ & $80 \pm 22$ & 0.1340 & \\
HD end & $157 \pm 52$ & $157 \pm 33$ & $142 \pm 24$ & 0.6700 & \\
LJD peak & $103 \pm 35$ & $63 \pm 21$ & $45 \pm 10$ & 0.0001 & $\mathrm{c}>\mathrm{p}>\mathrm{t}$ \\
LJE duration & $83 \pm 23$ & $45 \pm 16$ & $64 \pm 15$ & 0.0001 & $\mathrm{c}>\mathrm{t}>\mathrm{p}$ \\
UJP start & $108 \pm 34$ & $57 \pm 19$ & $41 \pm 12$ & 0.0001 & $\mathrm{c}>\mathrm{p}, \mathrm{t}$ \\
UJP duration & $62 \pm 23$ & $36 \pm 16$ & $44 \pm 13$ & 0.0052 & \\
UJP peak & $170 \pm 31$ & $99 \pm 23$ & $85 \pm 27$ & 0.0001 & $\mathrm{c}>\mathrm{p}, \mathrm{t}$ \\
UJR duration & $81 \pm 25$ & $83 \pm 21$ & $35 \pm 19$ & 0.0001 & $\mathrm{c}, \mathrm{p}>\mathrm{t}$ \\
UJR end & $250 \pm 29$ & $174 \pm 24$ & $120 \pm 23$ & 0.0008 & $\mathrm{c}>\mathrm{p}, \mathrm{t}$ \\
JC & $186 \pm 39$ & $108 \pm 22$ & $109 \pm 21$ & 0.0001 & $\mathrm{c}>\mathrm{p}, \mathrm{t}$ \\
HYD peak & $111 \pm 37$ & $73 \pm 27$ & $70 \pm 22$ & 0.006 & \\
HBD peak & $220 \pm 39$ & $90 \pm 31$ & $100 \pm 25$ & 0.0001 & $\mathrm{c}>\mathrm{p}, \mathrm{t}$
\end{tabular}

Values are means \pm standard deviations (in ms) from four capture, process and transport events from each of three individuals.

Significant Bonferroni $P$-value $=0.003$.

SNK, results of Student-Newman-Keuls multiple-comparisons test; c, capture; $p$, process; $t$, transport.

HBD, hypobranchial depression; HD, head drop; HL, head lift; HYD, hyoid depression; JC, jaw closure; LJD, lower jaw depression; LJE, lower jaw elevation; UJP, upper jaw protrusion; UJR, upper jaw retraction.

(mean distance $0.102 \mathrm{~cm}$ ) but the prey moves backwards a greater distance (mean distance $1.74 \mathrm{~cm}$ ). Presumably, the prey is transported through the esophagus to the stomach by a swallowing mechanism. Occasionally, transport of shrimp or fish occurred directly after a capture event with no intervening manipulatory or processing behavior.

Feeding events in lower vertebrates are typically defined by four phases on the basis of cranial movements and include a preparatory phase, in which buccal compression may precede mouth opening assisting in suction production, an expansive phase, from the start of mouth opening to peak gape, a compressive phase, from peak gape to jaw closure, and a recovery phase, in which the cranial elements are returned to their resting position (Liem, 1979, 1980; Lauder, 1985). Since S. tiburo is a ram feeder, a preparatory phase was not expected and was not observed.

The expansive phase of ram captures begins with simultaneous lower jaw depression and head elevation (Figs 6, 7). The anterior end of the shark is flexed ventrally as it approaches the prey. The entire cranium of the shark may be lowered below the longitudinal axis of the fish. The lower jaw is usually drawn close to or along the substratum until it contacts the prey, which is then grasped by the lower jaw teeth. Peak head lift, although slight, occurs midway through the expansive phase. The specific time of onset and duration of head lift and head drop are highly variable. The compressive 


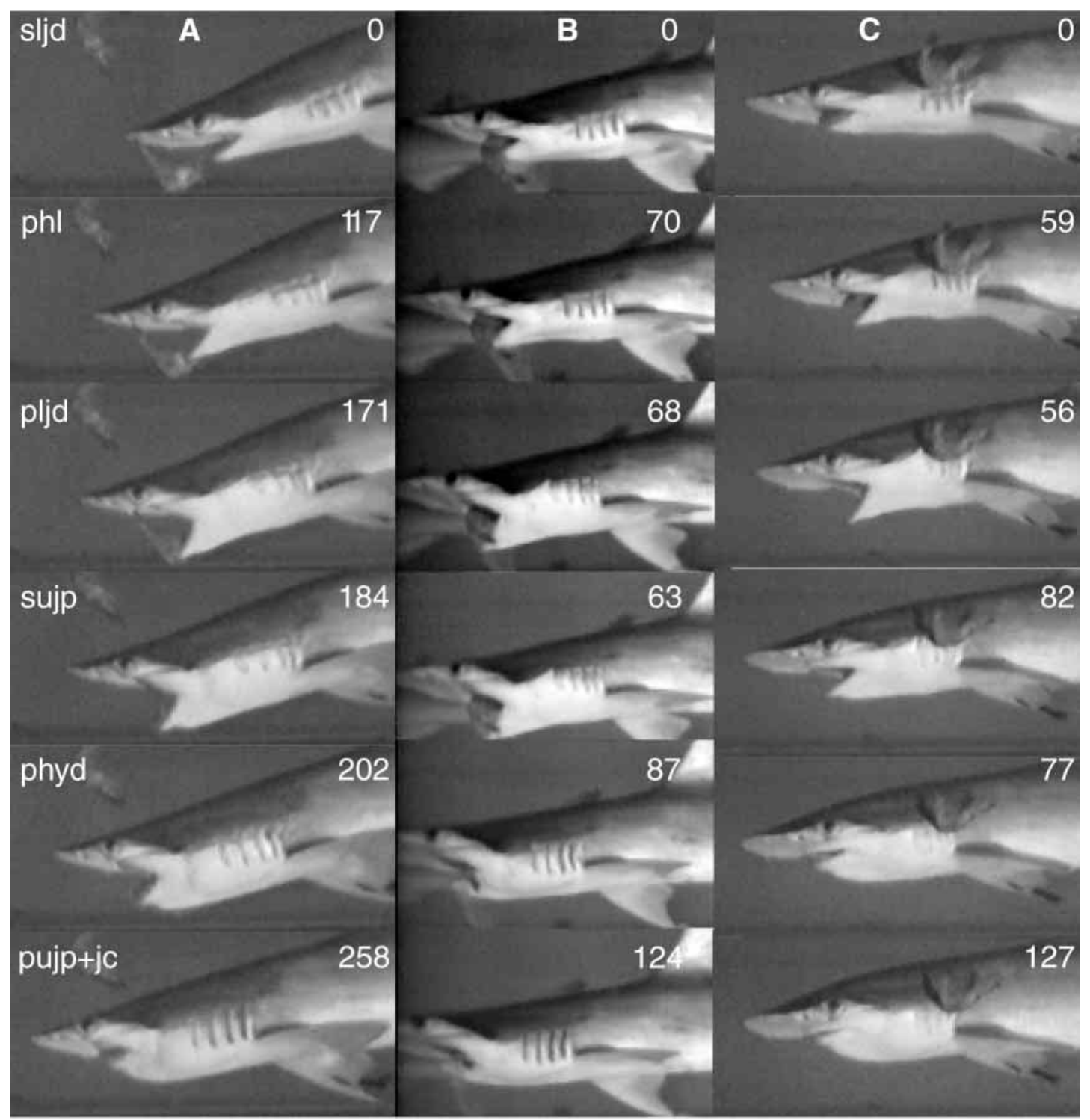

Fig. 6. Video images of a representative ram capture (A), crush processing (B) and suction transport (C) sequence in Sphyrna tiburo. Elasped times are shown in milliseconds. sljd, start of lower jaw depression; phl, peak head lift; pljd, peak lower jaw depression; sujp, start of upper jaw protrusion; phyd, peak hyoid depression; pujp, peak upper jaw protrusion; jc, jaw closure.

phase begins with elevation of the lower jaw and is followed by protrusion of the upper jaw. Peak hyoid depression occurs just after the lower jaw begins to elevate. Note that the lower jaw closes on the prey at the end of capture events, the beginning and end of processing events, and the beginning of transport events, as seen by the failure of the lower jaw to return to the resting position. This is also reflected in the gape, in which the upper and lower jaws do not meet because the prey is being held between the teeth. Upper jaw protrusion peaks just prior to complete jaw closure with the prey held between the jaws. During the recovery phase, the jaws are elevated back to the resting position. Upper jaw retraction is not completed until well after the jaws have closed. The mean duration of ram capture events from the start of lower jaw depression $(0 \mathrm{~ms})$ to the end of upper jaw retraction is $250 \mathrm{~ms}$
(Table 1). Hyoid depression is followed by hypobranchial depression in all types of feeding behavior, regardless of mechanism (ram capture or suction transport).

The kinematics of protrusion and lower jaw movements in crush processing and suction transport events differs from that of ram capture events (Figs 6, 7). In processing and transport events, the expansive phase begins with the prey already grasped between the jaws, as shown by the non-zero starting value for lower jaw depression and gape distance. In processing events, the jaws are opened from the initial nonresting position and the prey is moved to the region of the molariform teeth, where the jaws are then closed again. At the end of processing events, the jaws are closed again onto the prey such that the upper and lower jaws do not meet. The upper jaw remains partially protruded during the recovery phase in 

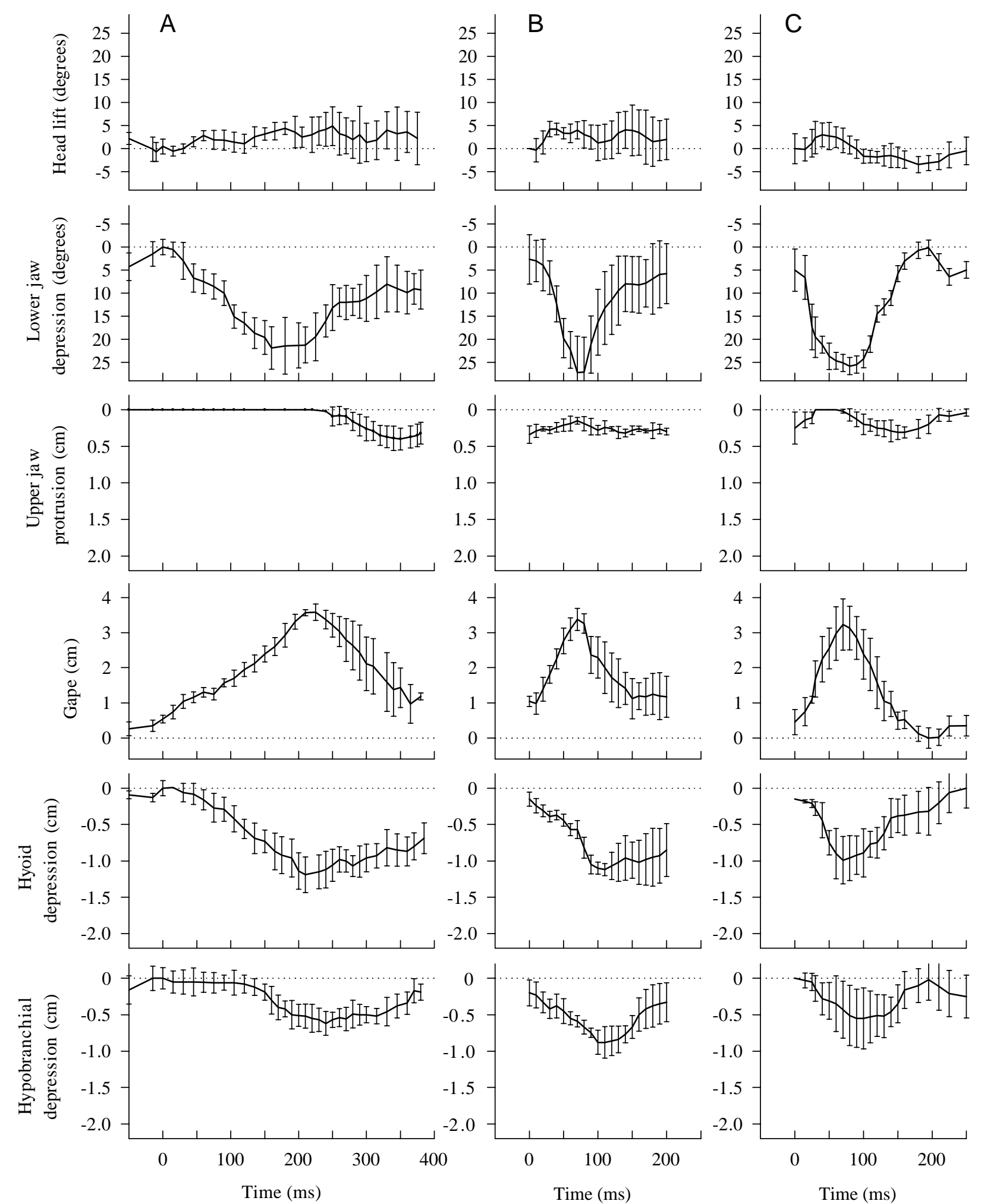

Fig. 7. Mean kinematic profiles of four capture (A), processing (B) and transport events (C). Mean displacements of head movements are shown from one representative individual Sphyrna tiburo. Axes are not scaled equivalently for all plots. Values are means \pm S.D.

crushing events since grasping of the prey prevents the upper jaw from retracting fully. Finally, the prey is moved from the jaws to the esophagus by suction during transport. The mean duration from the start of lower jaw depression $(0 \mathrm{~ms})$ to the end of upper jaw retraction is $174 \mathrm{~ms}$ for crush processing events and $120 \mathrm{~ms}$ for suction transport events (Table 1). 
Table 2. Statistical variables and results of ANOVA on the maximum magnitude of kinematic variables during ram capture, crush processing and suction transport events in Sphyrna tiburo

\begin{tabular}{lcccc}
\hline $\begin{array}{l}\text { Kinematic } \\
\text { variable }\end{array}$ & Capture & Process & Transport & $P$-value \\
\hline HL (degrees) & $8.99 \pm 5.1$ & $6.18 \pm 4.3$ & $6.91 \pm 5.74$ & 0.2085 \\
LJD (degrees) & $33.0 \pm 6.88$ & $31.8 \pm 13.61$ & $36.5 \pm 3.14$ & 0.2690 \\
GAP $(\mathrm{cm})$ & $3.87 \pm 0.51$ & $3.63 \pm 0.36$ & $4.22 \pm 0.75$ & 0.0686 \\
UJP $(\mathrm{cm})$ & $0.49 \pm 0.12$ & $0.50 \pm 0.10$ & $0.39 \pm 0.08$ & 0.0490 \\
HYD $(\mathrm{cm})$ & $1.47 \pm 0.36$ & $1.29 \pm 0.27$ & $1.82 \pm 0.32$ & 0.1649 \\
HBD $(\mathrm{cm})$ & $0.68 \pm 0.31$ & $1.28 \pm 0.44$ & $0.79 \pm 0.39$ & 0.0868
\end{tabular}

Values are means \pm standard deviation of four capture, process and transport events from each of three individuals.

Significant Bonferroni $P$-value $=0.008$.

GAP, gape; HBD, hypobranchial depression; HL, head lift; HYD, hyoid depression; LJD, lower jaw depression; UJP, upper jaw protrusion.

Statistical analysis of the kinematics during ram capture, crush processing and suction transport events reveals several differences (Table 1). Generally, the onset of jaw and hypobranchial kinematics occurs later in capture events than in processing and transport events because of the longer duration of lower jaw depression and elevation in capture events compared with processing and transport events. Consequently, upper jaw protrusion and retraction also occur later, since upper jaw protrusion does not occur until after peak lower jaw depression is reached. Upper jaw protrusion (mean peak $0.49 \mathrm{~cm}$ ) does not contribute significantly ( $t$-test,
Feeding mechanics of the hammerhead shark 2789

$P=0.191$, upper jaw protrusion versus gape minus upper jaw protrusion) towards reducing the gape (mean peak $3.87 \mathrm{~cm}$ ) (Table 2).

No differences in the magnitude of kinematics among the behaviors were detected (Table 2). This suggests that $S$. tiburo is capable of adjusting the velocity of cranial kinematics depending on behavior. Calculation of mean velocity reveals that depression of the lower jaw during processing and transport events is $2.5 \%$ and $3.3 \%$, respectively, more rapid than that during capture events.

No differences in kinematics according to prey type or hardness were detected (Table 3). Although the number of prey types was the same (capture, processing) or similar (transports), the sample sizes may be too small to reveal differences among the prey types. Also, if individual variation is high, then combining individual data in a one-way analysis may make it harder to detect differences by prey type.

\section{Motor activity patterns}

Representative EMG tracings from a ram capture, crush processing and suction transport event in the same individual show the motor pattern of the muscles (Fig. 8). Initial head depression is probably due to contraction of the hypaxial muscle (not implanted), as Nakaya (1995) found in S. lewini. The expansive phase (Fig. 8, between dotted lines 1 and 2) is characterized by activity in the jaw depressor and cranial levator muscles (Fig. 9). Activity in the coracomandibularis muscle begins just before the start of lower jaw depression and ends just before peak lower jaw depression. Activity in the epaxialis muscle begins immediately prior to the start of head lift and ends immediately before peak head lift. The hyoid

Table 3. Means of kinematic variables by prey type in Sphyrna tiburo

\begin{tabular}{|c|c|c|c|c|c|c|c|c|c|}
\hline \multirow[b]{2}{*}{$\begin{array}{l}\text { Kinematic } \\
\text { variable }\end{array}$} & \multicolumn{3}{|c|}{ Capture } & \multicolumn{3}{|c|}{ Process } & \multicolumn{3}{|c|}{ Transport } \\
\hline & $\begin{array}{l}\text { Crab } \\
(N=4)\end{array}$ & $\begin{array}{l}\text { Shrimp } \\
(N=4)\end{array}$ & $\begin{array}{l}\text { Fish } \\
(N=4)\end{array}$ & $\begin{array}{l}\text { Crab } \\
(N=4)\end{array}$ & $\begin{array}{l}\text { Shrimp } \\
(N=4)\end{array}$ & $\begin{array}{l}\text { Fish } \\
(N=4)\end{array}$ & $\begin{array}{l}\text { Crab } \\
(N=3)\end{array}$ & $\begin{array}{l}\text { Shrimp } \\
(N=4)\end{array}$ & $\begin{array}{l}\text { Fish } \\
(N=5)\end{array}$ \\
\hline HL dur & $35 \pm 15$ & $48 \pm 19$ & $56 \pm 23$ & $67 \pm 18$ & $62 \pm 23$ & $58 \pm 11$ & $80 \pm 32$ & $69 \pm 37$ & $87 \pm 38$ \\
\hline HL peak & $12 \pm 52$ & $40 \pm 31$ & $81 \pm 40$ & $58 \pm 19$ & $65 \pm 24$ & $72 \pm 21$ & $52 \pm 23$ & $64 \pm 15$ & $63 \pm 26$ \\
\hline HD dur & $93 \pm 40$ & $135 \pm 32$ & $154 \pm 49$ & $95 \pm 27$ & $94 \pm 35$ & $96 \pm 22$ & $87 \pm 32$ & $83 \pm 25$ & $74 \pm 20$ \\
\hline LJE dur & $77 \pm 33$ & $81 \pm 14$ & $91 \pm 18$ & $37 \pm 12$ & $52 \pm 21$ & $47 \pm 15$ & $75 \pm 27$ & $60 \pm 15$ & $63 \pm 23$ \\
\hline UJP start & $107 \pm 32$ & $126 \pm 57$ & $96 \pm 36$ & $50 \pm 14$ & $57 \pm 25$ & $63 \pm 24$ & $40 \pm 21$ & $41 \pm 15$ & $42 \pm 12$ \\
\hline UJP dur & $64 \pm 33$ & $61 \pm 53$ & $60 \pm 23$ & $30 \pm 12$ & $45 \pm 27$ & $34 \pm 20$ & $47 \pm 24$ & $43 \pm 17$ & $43 \pm 17$ \\
\hline UJP peak & $171 \pm 61$ & $180 \pm 31$ & $157 \pm 28$ & $80 \pm 16$ & $105 \pm 39$ & $110 \pm 19$ & $87 \pm 33$ & $84 \pm 25$ & $85 \pm 34$ \\
\hline UJR dur & $67 \pm 27$ & $75 \pm 45$ & $100 \pm 21$ & $77 \pm 24$ & $82 \pm 23$ & $89 \pm 27$ & $40 \pm 18$ & $32 \pm 10$ & $36 \pm 19$ \\
\hline
\end{tabular}

Values are means \pm standard deviations (in ms) of four capture, process and transport events from each of three individuals; $N$ represents the number of individual trials for each prey type.

dur, duration; HD, head drop; HL, head lift; HYD, hyoid depression; JC, jaw closure; LJD, lower jaw depression; LJE, lower jaw elevation; UJP, upper jaw protrusion; UJR, upper jaw retraction.

No effects of prey type reached significance at Bonferroni $P$-values of 0.003 . 
Fig. 8. Electromyographic profile of six muscles during representative examples of ram capture on crab, crush processing on crab and suction transport on fish in Sphyrna tiburo. The line drawings (from a ram capture) above the traces and the dotted lines on the traces illustrate major kinematic events: 1 , ljds, lower jaw depression start; 2 , ljdp, lower jaw depression peak; 3, ujpp, upper jaw protrusion peak; 4, jc, jaw closure; 5 , ejc, extended jaw closure ends. The elliptical area around the eye represents the 'hammer'. EP, epaxialis; CM, coracomandibularis; LH, levator hyomandibularis; LP, levator palatoquadrati; POV, ventral preorbitalis; QMD, dorsal quadratomandibularis. The scale bar on the lower left indicates $200 \mathrm{~ms}$.
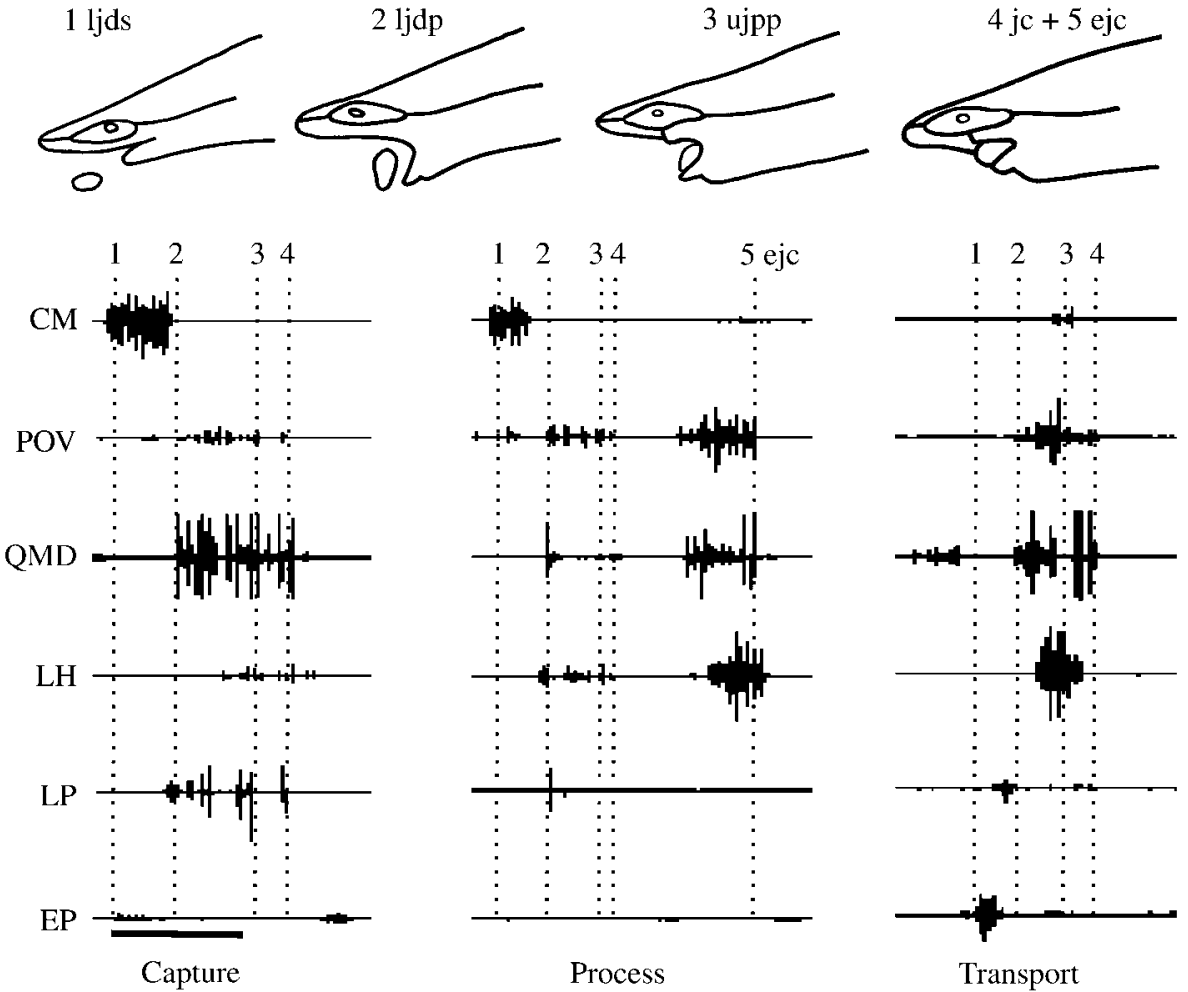

is depressed posteroventrally by the coracohyoideus and coracoarcualis muscles during feeding in $N$. brevirostris (Motta et al., 1997) and Squalus acanthias (Wilga and Motta, 1998a) and presumably also in Sphyrna tiburo.

The compressive phase (Fig. 8, between dotted lines 2 and 4) is characterized by activity in the jaw adductor and upper jaw protrusor muscles (Fig. 9). Activity in the dorsal quadratomandibularis muscle begins immediately prior to the start of lower jaw elevation and ends immediately after complete closure of the jaws. Protrusion of the upper jaw is achieved by coordinated activity in the preorbitalis and levator palatoquadrati muscles. Ventral preorbitalis muscle activity begins just prior the onset of upper jaw protrusion and ends immediately after peak upper jaw protrusion. Activity in the levator palatoquadrati muscle begins just prior to the onset of upper jaw protrusion and ends just before peak upper jaw protrusion. Upper jaw protrusion is limited by the relatively short ethmopalatine ligament connecting the upper jaw to the ectethmoid process of the chondrocranium and by the surrounding skin and connective tissue. The quadratomandibularis may assist in protruding the upper jaw as it adducts the jaws by pulling it ventrally. Protrusion of the upper jaw does not contribute significantly towards reducing the gape; thus, jaw closure is primarily due to elevation of the lower jaw, with only $13 \%$ attributable to protrusion of the upper jaw.

The recovery phase is characterized by activity of the levator hyomandibularis muscle, in which activity begins immediately prior to upper jaw retraction and just before complete jaw closure (Fig. 9). The levator hyomandibularis retracts the jaws by pulling the hyomandibula dorsally, which in turn is attached to the jaws at the jaw joint, resulting in retraction of the jaws as well as the hyoid back into their resting position (Fig. 9).

Detailed comparison of kinematics and motor activity

Table 4. Statistical variables and results of ANOVA on the timing of motor patterns in ram capture, crush processing and suction transport events in Sphyrna tiburo

\begin{tabular}{lrcccc}
\hline Muscle & Capture & Process & Transport & $P$-value & SNK \\
\hline CM onset & $-20 \pm 20$ & $-11 \pm 6$ & $18 \pm 5$ & 0.0003 & $\mathrm{c}, \mathrm{p}<\mathrm{t}$ \\
CM duration & $103 \pm 44$ & $46 \pm 22$ & $39 \pm 14$ & 0.0001 & $\mathrm{c}>\mathrm{p}, \mathrm{t}$ \\
EP onset & $2 \pm 54$ & $16 \pm 33$ & $9 \pm 5$ & 0.8813 & \\
EP duration & $37 \pm 22$ & $52 \pm 21$ & $14 \pm 6$ & 0.2862 & \\
QM onset & $98 \pm 48$ & $61 \pm 25$ & $35 \pm 17$ & 0.0002 & $\mathrm{c}>\mathrm{p}, \mathrm{t}$ \\
QM duration & $99 \pm 40$ & $104 \pm 36$ & $50 \pm 24$ & 0.0004 & $\mathrm{c}, \mathrm{p}>\mathrm{t}$ \\
PO onset & $88 \pm 46$ & $65 \pm 28$ & $26 \pm 6$ & 0.0006 & $\mathrm{c}, \mathrm{p}>\mathrm{t}$ \\
PO duration & $66 \pm 29$ & $65 \pm 20$ & $55 \pm 25$ & 0.6567 & \\
LP onset & $99 \pm 52$ & $56 \pm 25$ & $46 \pm 10$ & 0.0246 & \\
LP duration & $26 \pm 15$ & $40 \pm 21$ & $6 \pm 12$ & 0.0071 & \\
LH onset & $160 \pm 24$ & $107 \pm 38$ & $48 \pm 10$ & 0.0001 & $\mathrm{c}>\mathrm{p}>\mathrm{t}$ \\
LH duration & $33 \pm 27$ & $47 \pm 33$ & $67 \pm 24$ & 0.0665 &
\end{tabular}

Values are means \pm standard deviations (in $\mathrm{ms}$ ).

Significant Bonferroni $P$-value $=0.004$.

SNK, results of Student-Newman-Keuls multiple comparisons test. Means are for four capture, process and transport events from each of three individuals.

c, capture; p, process; t, transport; CM, coracomandibularis; EP, epaxialis; LH, levator hyomandibularis; LP, levator palatoquadrati; PO, preorbitalis; QM, quadratomandibularis. 

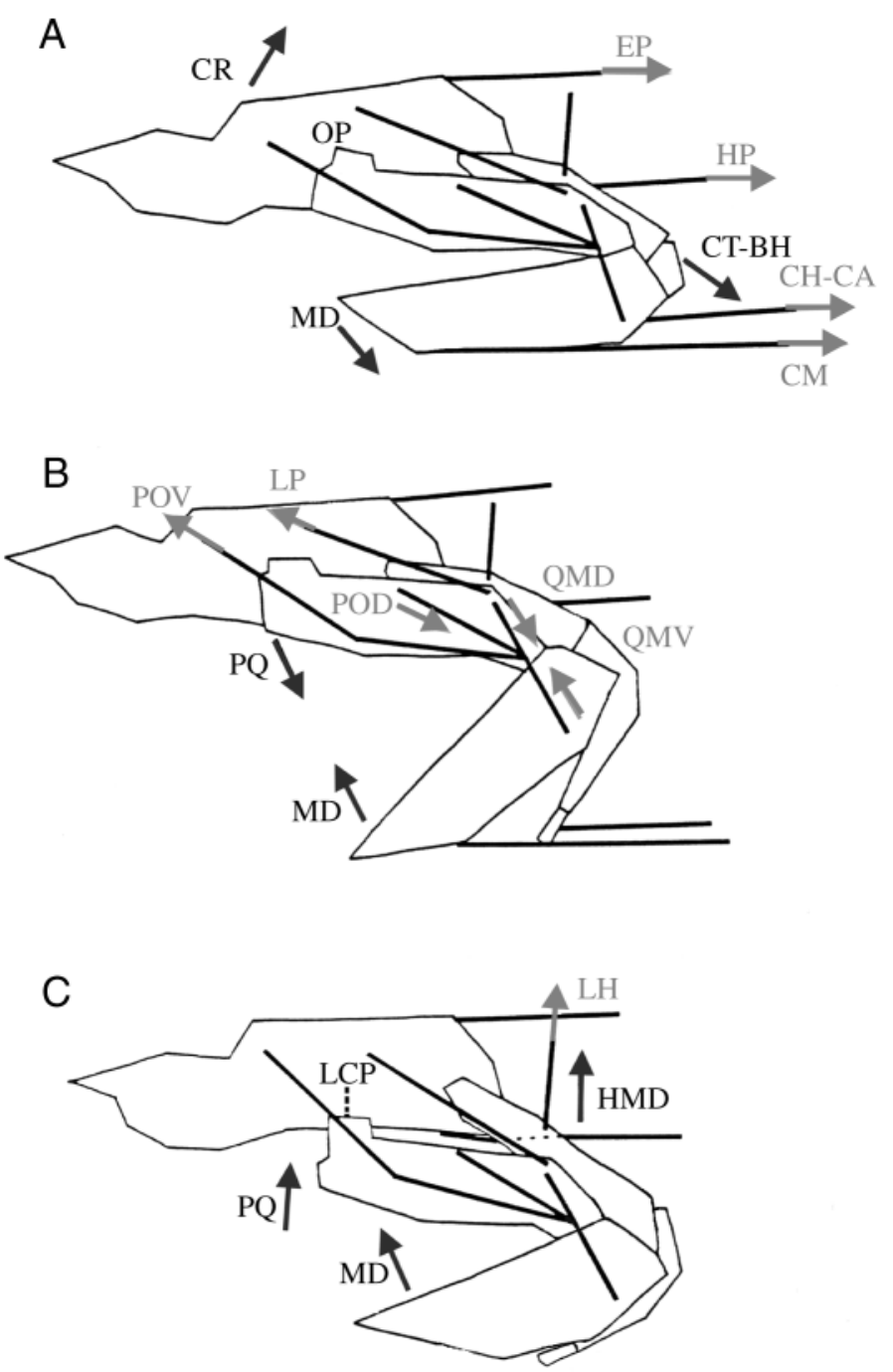

Fig. 9. Schematic diagram of the functional components involved in jaw protrusion and retraction in Sphyrna tiburo. (A) Resting position; (B) peak gape; (C) peak upper jaw protrusion. See text for details. Black arrows indicate movements of the head and jaw elements, thick lines indicate muscles and grey arrows indicate the direction of muscle contraction. $\mathrm{CR}$, cranium; $\mathrm{CH}-\mathrm{CA}$, coracohyoideus-coracoarcualis complex; CM, coracomandibularis; CT-BH, ceratohyal-basihyal complex; EP, epaxialis; HMD, hyomandibula; HP, hypaxialis; LCP, ethmopalatine ligament; LH, levator hyomandibularis; LP, levator palatoquadrati; MD, mandible or lower jaw; OP, orbital process of palatoquadrate; POD, dorsal preorbitalis; POV, ventral preorbitalis; $\mathrm{PQ}$, palatoquadrate cartilage or upper jaw; QMD, dorsal quadratomandibularis; QMV, ventral quadratomandibularis.

among capture, processing and transport events during the electromyography experiments (Table 4) reveals a major functional difference in feeding mechanics that may be attributed to durophagous behavior. In processing events only, activity in the dorsal quadratomandibularis muscle does not end at jaw closure as in capture and transport events, but continues until well after complete closure of the jaws and may even extend until the end of the recovery phase (Fig. 8).
Quadratomandibularis activity ends $11 \mathrm{~ms}$ after, $57 \mathrm{~ms}$ after and $24 \mathrm{~ms}$ prior to jaw closure in capture, process and transport events respectively. Even though the overall duration of quadratomandibularis activity does not differ between capture and processing events, the jaw is already closed during processing as the muscle continues to contract. In addition, the duration of motor activity in the coracomandibularis muscle in capture events is also significantly longer than in processing or transport events, reflecting the longer duration of lower jaw depression (Table 4).

In suction transport events, a preparatory phase is occasionally observed prior to mouth opening. A small burst of activity in the quadratomandibularis muscle may occur just before lower jaw depression, indicating that compression of the buccal cavity may be occurring (see Fig. 8). In suction transport events, a large burst of activity in the levator hyomandibularis muscle occurs after the onset of lower jaw elevation in the compressive phase.

No differences in motor pattern according to prey type or hardness were detected (Table 5). Although the number of prey items was the same (capture, processing) or similar (transports), the sample sizes may be too small to reveal differences among the prey types. Also, if individual variation is high, then combining individual data in a one-way analysis may make it harder to detect differences by prey type.

\section{Discussion}

The bonnethead shark Sphyrna tiburo uses ram feeding to capture the crab, shrimp and fish presented in this study. Following capture, the prey is processed, which involves placing the prey between the molariform teeth where it is crushed. Finally, suction is used to transport the prey to the esophagus for swallowing. By combining a suite of durophagous characteristics with altered kinematic and motor patterns, S. tiburo takes advantage of a resource that is not readily available to most sharks. The duration of jaw adductor muscle activity is prolonged and jaw kinematics modified during processing, indicating that the jaws are continuing to crush prey well after they have closed. This characteristic appears to distinguish prey crushing from simply biting in elasmobranchs. No differences were found in kinematic or motor patterns when feeding on prey of different hardness, indicating that $S$. tiburo consumes crab, shrimp and pieces of fish similarly. This suite of morphological, behavioral and physiological characteristics permits Sphyrna tiburo to specialize on crabs (which make up over $92 \%$ IRI, index of relative importance, of its diet) (Cortes et al., 1996; Lessa and Almeida, 1998), yet apparently restricts its ability to modulate its feeding behavior when feeding on other prey.

\section{Strategies for durophagy}

Hard-shelled prey require special processing to break the protective armor for easier swallowing and digestion. Several morphological and functional characteristics appear to allow Sphyrna tiburo to specialize on hard-shelled prey that are 
Table 5. Mean timing of motor pattern variables by prey type in Sphyrna tiburo

\begin{tabular}{|c|c|c|c|c|c|c|c|c|c|}
\hline \multirow[b]{2}{*}{ Muscle } & \multicolumn{3}{|c|}{ Capture } & \multicolumn{3}{|c|}{ Process } & \multicolumn{3}{|c|}{ Transport } \\
\hline & $\begin{array}{l}\text { Crab } \\
(N=4)\end{array}$ & $\begin{array}{l}\text { Shrimp } \\
(N=4)\end{array}$ & $\begin{array}{l}\text { Fish } \\
(N=4)\end{array}$ & $\begin{array}{l}\text { Crab } \\
(N=4)\end{array}$ & $\begin{array}{l}\text { Shrimp } \\
(N=4)\end{array}$ & $\begin{array}{l}\text { Fish } \\
(N=4)\end{array}$ & $\begin{array}{c}\text { Crab } \\
(N=4)\end{array}$ & $\begin{array}{l}\text { Shrimp } \\
(N=4)\end{array}$ & $\begin{array}{c}\text { Fish } \\
(N=5)\end{array}$ \\
\hline $\mathrm{CM}$ ons & $-26 \pm 22$ & $-10 \pm 23$ & $-25 \pm 11$ & $-17 \pm 6$ & $-11 \pm 6$ & $-8 \pm 6$ & $16 \pm 5$ & $16 \pm 5$ & $20 \pm 6$ \\
\hline CM dur & $124 \pm 41$ & $95 \pm 14$ & $90 \pm 67$ & $50 \pm 27$ & $53 \pm 26$ & $38 \pm 19$ & $24 \pm 12$ & $43 \pm 11$ & $42 \pm 16$ \\
\hline EP on & $-61 \pm 77$ & $52 \pm 58$ & $14 \pm 68$ & $10 \pm 43$ & $31 \pm 49$ & $12 \pm 11$ & $12 \pm 5$ & $9 \pm 6$ & $7 \pm 4$ \\
\hline EP dur & $24 \pm 10$ & $45 \pm 20$ & $41 \pm 29$ & $15 \pm 10$ & $14 \pm 20$ & $32 \pm 24$ & $12 \pm 6$ & $15 \pm 7$ & $16 \pm 6$ \\
\hline $\mathrm{QM}$ on & $117 \pm 43$ & $90 \pm 38$ & $87 \pm 65$ & $57 \pm 19$ & $80 \pm 19$ & $57 \pm 29$ & $35 \pm 102$ & $31 \pm 12$ & $38 \pm 11$ \\
\hline QMs dur & $106 \pm 41$ & $77 \pm 25$ & $113 \pm 52$ & $162 \pm 44$ & $107 \pm 50$ & $67 \pm 24$ & $56 \pm 23$ & $35 \pm 21$ & $63 \pm 27$ \\
\hline PO on & $107 \pm 54$ & $95 \pm 49$ & $61 \pm 31$ & $46 \pm 21$ & $85 \pm 21$ & $69 \pm 32$ & $26 \pm 12$ & $21 \pm 13$ & $31 \pm 14$ \\
\hline $\mathrm{PO}$ dur & $55 \pm 38$ & $69 \pm 30$ & $74 \pm 20$ & $88 \pm 59$ & $44 \pm 21$ & $59 \pm 29$ & $71 \pm 40$ & $46 \pm 26$ & $57 \pm 19$ \\
\hline LP on & $110 \pm 57$ & $81 \pm 51$ & $104 \pm 59$ & $49 \pm 38$ & $61 \pm 32$ & $60 \pm 21$ & $46 \pm 18$ & $45 \pm 21$ & $47 \pm 12$ \\
\hline LP dur & $30 \pm 18$ & $20 \pm 15$ & $26 \pm 13$ & $51 \pm 33$ & $26 \pm 20$ & $40 \pm 15$ & $6 \pm 5$ & $5 \pm 8$ & $7 \pm 6$ \\
\hline LH on & $166 \pm 29$ & $143 \pm 28$ & $170 \pm 22$ & $108 \pm 45$ & $94 \pm 36$ & $115 \pm 47$ & $62 \pm 17$ & $41 \pm 17$ & $49 \pm 14$ \\
\hline LH dur & $49 \pm 45$ & $20 \pm 9$ & $30 \pm 8$ & $59 \pm 20$ & $25 \pm 15$ & $49 \pm 23$ & $39 \pm 18$ & $62 \pm 20$ & $83 \pm 27$ \\
\hline
\end{tabular}

Values are means \pm standard deviations (in $\mathrm{ms}$ ) of four capture, process and transport events from each of three individuals.

CM, coracomandibularis; dur, duration; EP, epaxialis; LH, levator hyomandibularis; LP, levator palatoquadrati; on, onset; PO, preorbitalis; QM, quadratomandibularis.

No effects of prey type reached significance at Bonferroni $P$-values of 0.003 .

unavailable to many fishes: alteration of motor activity in the jaw adductor muscles, modification of jaw kinematics, an extended insertion of the upper jaw protrusor muscle, reduced upper jaw mobility and durophagus tooth morphology. The altered motor activity of the quadratomandibularis and preorbitalis muscles when processing hard prey results in the extension of muscle contraction past jaw closure and into a second phase of jaw closure, well beyond that during the capture and transport of hard prey. This is in contrast to the queen triggerfish Balistes vetula, in which the motor pattern of bite captures were indistinguishable from bite processing on crab (Turingan and Wainwright, 1993). Like S. tiburo, Atlantic sheepshead Archosargus probatocephalus manipulate hardshelled prey to the molariform teeth, where the prey is then crushed (Hernandez and Motta, 1997).

Simultaneous electromyography and video analyses were not presented in these studies, so it is not known whether initial closing of the jaws onto hard prey is sufficient or if additional adduction is required to crush it. This distinction is crucial, because different strategies may be used to crush hard prey. Organisms with hypertrophied adductor musculature and robust jaws, such as those of triggerfish and sheepshead (Turingan and Wainwright, 1993; Hernandez and Motta, 1997), may be capable of crushing hard prey during capture. Alternatively, organisms with less specialized morphology, such as bonnethead sharks, may require the prey to be repositioned to a more strategic location within the mouth, such as between the posterior molariform teeth, and a longer period of adduction of the jaws during processing to crush or disable hard prey. A strategy similar to this is found in teleost fishes that crush hard prey in the pharyngeal jaws. During prey processing in these bony fishes, the prey is often transported hydraulically to the molariform pharyngeal teeth, where the hypertrophied pharyngeal muscles crush the prey (Wainwright,
1987, 1988). Prolonged biting using the posterior molariform teeth may be used to crack the hard shells of crab to facilitate swallowing and digestion or to disable the prey, as reflected in the prolonged motor activity of the jaw adductors during processing.

The morphology of the upper jaw protrusor muscle may be advantageous in crushing behavior. The dorsal preorbitalis muscle has a broad and more posterior insertion on the upper jaw that parallels the region of molariform teeth on the upper jaw compared with that of the carcharhiniform lemon shark Negaprion brevirostris (Motta and Wilga, 1995). This arrangement favors force transmission of muscle contraction along the molariform teeth of the upper jaw (Loeb and Gans, 1986) and may increase the crushing force of the upper jaw onto hard prey as the jaws are being adducted. In support of this, preorbitalis muscle bursts are qualitatively larger during processing events than capture events.

Reduced mobility of the upper jaw is often regarded as a specialization for durophagy in bony fishes (Turingan and Wainwright, 1993). Sphyrna tiburo exhibits negligible protrusion of the upper jaw compared with other sharks as the result of a relatively firm connection between the cranium and the upper jaw (Motta and Wilga, 2000). The ventral preorbitalis and levator palatoquadrati muscles place an anteriorly directed force on the posterior region of the upper jaw, which forces the orbital process of the upper jaw to slide ventrally along the ethmopalatine groove of the cranium into the protruded position. A relatively short ethmopalatine ligament connects the upper jaw to the cranium, restricting its mobility. This tighter connection provides a relatively rigid and immovable upper jaw. In the retracted position, the orbital process lies in the ethmopalatine groove and resists anterior and lateral movement of the upper jaw, such as may occur during prolonged biting or crushing. Together, these increase 
the support and bracing of the upper jaw against the cranium, particularly in transmitting crushing forces during processing of hard-shelled prey (Barel, 1983; Otten, 1983).

Sphyrna tiburo is unique among hammerhead sharks in possessing molariform teeth in the posterior dental area. Molariform teeth are present at birth in S. tiburo (C. Manire, personal communication); therefore, the cusps are not worn down by consumption of hard prey. This feature appears to be the only morphological characteristic of $S$. tiburo that is not possessed by other hammerhead sharks, although a detailed morphological study of the cranial musculature of hammerhead sharks is needed. It is possible that its small size (130-150 cm TL for adults) and molariform teeth allow $S$. tiburo to forage in seagrass beds and take advantage of a resource not available to other hammerhead sharks. The diet of other hammerhead sharks is dominated by fish (Clarke, 1971; Compagno, 1984, 1988; Wetherbee et al., 1990; Stevens and Lyle, 1989; Strong et al., 1990).

The crushing mechanism in S. tiburo is somewhat similar to that of horn sharks (Heterodontiformes). Horn sharks are the only other sharks that possess molariform teeth; however, unlike $S$. tiburo, they have robust jaws and hypertrophied adductor musculature. After capture, horn sharks crush their hard-shelled prey using several processing bites to reduce it prior to swallowing (Pretlow-Edmonds, 1999). Similar to $S$. tiburo, the line of action of the upper jaw protrusor and jaw adductor muscles in Heterodontus philippi appears to be in a position to generate their greatest force in the region of the molariform teeth (Nobiling, 1977).

Guitarfish and stingrays appear to use divergent mechanisms to feed on hard prey. Atlantic guitarfish Rhinobatos lentiginosus have a crushing dentition similar to that of Raja spp. (Fig. 2) and feed on relatively hard-shelled prey, such as mole crabs and shrimp. Similar to S. tiburo, activity in the quadratomandibularis and preorbitalis muscles is also prolonged and continues well past jaw closure during crush processing events compared with capture and transport events (Wilga and Motta, 1998b). However, in myliobatid stingrays, the mechanism is very different from that of sharks and guitarfish, in which crushing appears to occur more towards the symphyses rather than towards the jaw joint, as in horn and bonnethead sharks. Crucial to this mechanism is fusion of the palatoquadrate and mandibular symphyses overlaid by pavement-like tooth plates, calcified strengthened jaws containing calcified struts, a restricted gape and asynchronous activation of the jaw adductors with a force-amplifying lever system similar to a nutcracker (Summers, 2000). The bonnethead $S$. tiburo is capable of crushing crabs without such morphological specializations as fused tooth plates and fused symphyses. Asynchronous adductor activity, however, has not yet been investigated in sharks.

The ancestral mechanism for crushing, such as that in smoothhounds and guitarfish, might have simply involved a modified motor pattern of the jaw muscles and slightly modified teeth. More derived mechanisms for crushing allowing for the consumption of relatively harder prey appeared with the development of molariform teeth and modification of the jaw muscles, such as in bonnethead and horn sharks. Finally, with features such as pavement-like tooth plates, fused mandibular and palatoquadrate symphyses and calcified struts within the jaws, the most derived crushing mechanism, grinding, evolved in durophagous myliobatid rays. More studies are needed on crushing and grinding in chondrichthyans to understand better the evolution of crushing mechanisms.

\section{Variation among prey types}

No differences in response to prey hardness were found in any of the kinematic or motor pattern variables, indicating that S. tiburo does not modulate its feeding behavior when feeding on crab, shrimp and fish pieces. The bonnethead shark is a dietary specialist, with over $92 \%$ (IRI) of its diet consisting of crabs (Cortes et al., 1996; Lessa and Almeida, 1998). Several studies have documented the lack of modulation in preycapture behavior by prey type, size or elusivity in aquatic vertebrates, axolotls Ambystoma mexicanum (Reilly and Lauder, 1989), swellsharks Cephaloscyllium ventriosum (Ferry-Graham, 1997) and leopard sharks Triakis semifasciata (Ferry-Graham, 1998). All these studies reported significant individual variation among feeding trials that was greater than the variation among prey categories. The lack of modulation in response to prey type in $S$. tiburo appears to be a real biological phenomenon. In contrast, modulation in feeding behavior was found in another durophagous feeder, Balistes vetula, in which capture and processing of crab prey elicited significantly longer adductor activity compared with soft prey (Wainwright and Turingan, 1993).

\section{Variation among feeding behaviors}

The bonnethead shark Sphyrna tiburo captures its prey by ram feeding. It has been predicted that ram feeders should have a large gape, a large buccal area-to-volume ratio and a body morphology that contributes to rapid acceleration of the body (Norton, 1995). Fishes that bite their prey are predicted to have hypertrophied musculature and powerful jaws with a cutting or crushing dentition. Sphyrna tiburo are relatively fast cruising and agile pelagic sharks (Nakaya, 1995) that are readily capable of pursuing and catching elusive prey such as portunid crabs. In Florida and Brazilian waters, Sphyrna tiburo feed almost exclusively on portunid crabs (Compagno, 1984; Cortes et al., 1996; Lessa and Almeida, 1998), which are agile pelagic swimmers capable of turning rapidly in any direction (Barnes, 1968). The large gape angle, lack of lateral labial folds to enclose the gape, rapid and agile cruising behavior and crushing dentition indicate that Sphyrna tiburo has characteristics of both ram and bite feeders.

Differences among the feeding behaviors are mainly due to variations in jaw opening, jaw closing and protrusion movements. Overall, ram capture events are twice as long as crush processing and suction transport events, as indicated by the later onset times of jaw depression (coracomandibularis), elevation (quadratomandibularis), protrusion (preorbitalis) and 
retraction (levator hyomandibularis) variables (Tables 1, 4). More specifically, jaw-closing kinematics and jaw adductor activity clearly distinguish crush processing events from capture and transport events. After the jaws initially close onto the prey in crush processing, there is a short pause after which the jaw resumes closing onto the prey (see plateau near the end of lower jaw depression in Fig. 7). It is during this second period of lower jaw elevation, well after the jaws have closed, that large bursts of activity occur in the quadratomandibularis (jaw adductor), preorbitalis (upper jaw protrusor) and levator hyomandibularis (jaw elevator) muscles. It is possible that during this plateau phase the jaws are applying pressure to the prey until it is crushed, after which the jaws resume their motion. The upper jaw virtually maintains its protruded position throughout crush processing, unlike capture and transport events, when the upper jaw cycles between complete peak protrusion and retraction. This is supported by the near doubling of preorbitalis activity (compared with upper jaw protrusion duration) during processing compared with captures and transports. Thus, simultaneously, the jaws are adducted and the upper jaw is protruded as the jaw apparatus is braced against the cranium. This extended biting activity after jaw closure during processing events may be a mechanism for crushing or disabling hard prey prior to swallowing.

All elasmobranchs examined to date utilize suction to transport prey (Ferry-Graham, 1997, 1998; Motta et al., 1997; Wilga and Motta, 1998a,b), including the bonnethead Sphyrna tiburo. A preparatory reduction in buccal volume during suction transport events may increase the amount of suction that S. tiburo generates to transport the prey to the esophageal region. Also, early elevation of the hyoid arch by the levator hyomandibularis muscle in suction transport events, compared with capture and processing events, may assist in compressing the buccal cavity, thereby pushing water and prey posteriorly towards the esophagus. In $S$. tiburo, the magnitude of hyoid and hypobranchial depression in processing and transports is similar to that of capture events; however, it occurs in a significantly shorter period during processing and transport. This implies that buccal expansion occurs at a greater velocity during these events, increasing suction inflow. Similar results were found when comparing capture and transport events in the swellshark Cephaloscyllium ventriosum (Ferry-Graham, 1997). Speed is an important factor in the generation of suction: the faster the hyoid and hypobranchial region can expand, the greater the suction inflow that can be produced (Osse, 1969; Liem, 1980; Lauder, 1980; Muller and Osse, 1984).

In summary, the bonnethead shark Sphyrna tiburo uses ram feeding to capture its exclusive diet of hard-shelled elusive crabs, crushing the prey with its molariform teeth to process it and using suction to transport the prey to the esophagus for swallowing. By altering the duration of jaw adductor muscle activity and modifying its jaw kinematics, $S$. tiburo is able to crush its prey during a second jaw-closing phase characterized by prolonged activity of the adductor muscles after jaw closure. This characteristic appears to distinguish prey crushing from simply biting in elasmobranchs. By utilizing a suite of durophagous characteristics, $S$. tiburo takes advantage of a resource of hard prey that is not readily available to most sharks. This suite of specializations for feeding on hard prey may have contributed to its apparent lack of modulatory ability when feeding on other prey types. Comparison of capture and processing events in elasmobranchs indicates that functional patterns are altered and coupled with modifications in dental and jaw morphology to produce diverse crushing behaviors. More detailed quantitative studies are needed to assess the evolution of functional and morphological patterns associated with these diverse feeding behaviors.

The authors gratefully acknowledge the contributions of time, materials and assistance provided by Robert Hueter, Peter Wainwright, Charles Manire, John Tyminski, Heike Keuthen, Karen Overholtzer, Dawna Briner and Amee Cywinski. Mote Marine Laboratory and the University of South Florida provided facilities and equipment. The authors are indebted to Enric Cortes, Charles Manire and John Tyminski for providing footage of fresh-caught Sphyrna tiburo feeding in a semi-natural tank. This project was supported by an NRC Ford Foundation Predoctoral Fellowship, a Mote Marine Laboratory and University of South Florida Graduate Fellowship in Elasmobranch Biology, a USF Lesser Fund Scholarship and a Cook Inlet Region Grant to C.D.W. Equipment used in this research was supported by a National Science Foundation grant to P.J.M. (DEB 9117371). We thank Lara Ferry-Graham, Justin Grubich, Mark Westneat and two anonymous reviewers for providing helpful comments that greatly improved the manuscript.

\section{References}

Barel, C. D. N. (1983). Towards a constructional morphology of cichlid fishes (Teleostei: Perciformes). Neth. J. Zool. 33, 357-424.

Barnes, R. D. (1968). Invertebrate Zoology. Philadelphia: W. B. Saunders Co.

Bigelow, H. B. and Schroeder, W. (1953). Sawfishes, guitarfishes, skates and rays. In Fishes of the Western North Atlantic (ed. J. TeeVan), pp. 1-514. New Haven: Sears Foundation for Marine Research.

Buxton, C. D. (1984). Feeding biology of the roman Chrysoblephus laticeps (Pisces: Sparidae). S. Afr. J. Mar. Sci. 2, 33-42.

Buxton, C. D. and Clarke, J. R. (1989). The growth of Cymatoceps nasutus (Teleostei: Sparidae), with comments on diet and reproduction. S. Afr. J. Mar. Sci. 8, 57-65.

Buxton, C. D. and Clarke, J. R. (1991). The biology of the white musclecracker, Sparodon durbanensis (Pisces: Sparidae) on the Eastern Cape coast, South Africa. S. Afr. J. Mar. Sci., 8, 285-296.

Cappetta, H. (1987). Chondrichthyes. II. Mesozoic and Cenozoic Elasmobranchii. New York: Gustav Fischer Verlag.

Christiansen, M. S. (1978). Trophic relations in juveniles of three species of sparid fishes in the South African marine littoral. Fish. Bull. 76, 389-401.

Clarke, T. A. (1971). The ecology of the scalloped hammerhead shark, Sphyrna lewini, in Hawaii. Pac. Sci. 25, 133-144. 
Compagno, L. J. V. (1984). FAO Species Catalogue, vol. 4, Sharks of the World. Rome: Food and Agricultural Organization of the United Nations.

Compagno, L. J. V. (1988). Sharks of The Order Carcharhiniformes. Princeton, NJ: Princeton University Press.

Cortes, E., Manire, C. A. and Hueter, R. E. (1996). Diet, feeding habits and diel feeding chronology of the bonnethead shark, Sphyrna tiburo, in southwest Florida. Bull. Mar. Sci. 58, 353-367.

Daniel, J. F. (1922). The Elasmobranch Fishes. Berkeley, CA: University of California Press.

Dean, B. (1906). Chimaeroid Fishes and their Development. Washington: Carnegie Institution.

Di Giancomo, E. E. and Perier, M. R. (1996). Feeding habits of cockfish, Callorhinchus callorhynchus (Holocephali: Callorhynchidae), in Patagonian waters (Argentina). Mar. Freshwater Res. 47, 801-808.

Ebert, D. A., Cowley, P. D. and Compagno, L. J. V. (1991). A preliminary investigation of the feeding ecology of skates (Batoidea: Rajidae) off the west coast of Southern Africa. S. Afr. J. Mar Sci. 10, 71-81.

Ferry-Graham, L. A. (1997). Feeding kinematics of juvenile swellsharks, Cephaloscyllium ventriosum. J. Exp. Biol. 200, 1255-1269.

Ferry-Graham, L. A. (1998). Effects of prey size and mobility on prey-capture kinematics in leopard sharks Triakis semifasciata. J. Exp. Biol. 201, 2433-2444.

Frazzetta, T. H. (1994). Feeding mechanisms in sharks and other elasmobranchs. Adv. Comp. Env. Physiol. 18, 31-57.

Garman, S. (1913). The Plagiostoma. Mem. Mus. Comp. Zool. 36, pp. 515.

Gray, A. E., Mulligan, T. J. and Hannah, R. W. (1997). Food habits, occurrence and population structure of the bat ray, Myliobatis californica, in Humbolt Bay, California. Env. Biol. Fish. 49, 227-238.

Hernandez, L. P. and Motta, P. J. (1997). Trophic consequences of differential performance: ontogeny of oral jaw-crushing performance in the sheepshead, Archosargus probatocephalus (Teleostei, Sparidae). J. Zool., Lond. 243, 737-756.

Lauder, G. V. (1980). Hydrodynamics of prey capture by teleost fishes. In Biofluid Mechanics (ed. D. J. Schneck), pp. 161-181. New York: Plenum Press.

Lauder, G. V. (1985). Aquatic feeding in lower vertebrates. In Functional Vertebrate Morphology (ed. M. Hildebrand, D. M. Bramble, K. F. Liem and D. B. Wake), pp. 210-229. Cambridge, MA: Harvard University Press.

Lessa, R. P. and Almeida, Z. (1998). Feeding habits of the bonnethead shark, Sphyrna tiburo, from Northern Brazil. Cybium 22, 383-394.

Liem, K. F. (1979). Modulatory multiplicity in the feeding mechanism in cichlid fishes, as exemplified by the invertebrate pickers of Lake Tanganyika. J. Zool., Lond. 189, 93-125.

Liem, K. F. (1980). Adaptive significance of intra- and interspecific differences in the feeding repertoires of cichlid fishes. Am. Zool. 20, 295-314.

Loeb, G. E. and Gans, C. (1986). Electromyography for Experimentalists. Chicago: The University of Chicago Press.

Moss, S. A. (1972). The feeding mechanism of sharks of the family Carcharhinidae. J. Zool., Lond. 167, 423-436.

Moss, S. A. (1977). Feeding mechanisms in sharks. Am. Zool. 17, 355-364.
Motta, P. J., Tricas, T. C., Hueter, R. E. and Summers, A. P. (1997). Feeding mechanism and functional morphology of the jaws of the lemon shark, Negaprion brevirostris (Chondrichthyes, Carcharhinidae). J. Exp. Biol. 200, 2765-2780.

Motta, P. J. and Wilga, C. D. (1995). Anatomy of the feeding apparatus of the lemon shark, Negaprion brevirostris. J. Morph. 226, 309-329.

Motta, P. J. and Wilga, C. D. (2000). Advances in the study of feeding mechanisms, mechanics and behaviors of sharks. In Biology and Sensory Biology of Sharks: Past, Present and Future Studies (ed. S. Gruber and T. Tricas). Dev. Env. Biol. Fish. (in press).

Muller, M. and Osse, J. M. W. (1984). Hydrodynamics of suction feeding in fish. Trans. Zool. Soc. Lond. 37, 51-135.

Nakaya, K. (1995). Hydrodynamic function of the head in the hammerhead sharks (Elasmobranchii: Sphyrnidae). Copeia 1995, 330-336.

Nobiling, G. (1977). Die Biomechanik des Kiefferapparates beim Stierkopfhai (Heterodontus portusjacksoni=Heterodontus philippi). Adv. Anat. Embryol. Cell Biol. 52, 1-52.

Norton, S. F. (1995). A functional approach to ecomorphological patterns of feeding in cottid fishes. Env. Biol. Fish. 44, 61-78.

Osse, J. W. M. (1969). Functional morphology of the head of the perch (Perca fluviatilis L.): an electromyographic study. Neth. J. Zool. 19, 289-392.

Otten, E. (1983). The jaw mechanism during growth of a generalized Haplochromis species: H. elegans Trewavas, 1933 (Pisces, Cichlidae). Neth. J. Zool. 33, 55-98.

Pretlow-Edmonds, M. (1999). Prey capture kinematics of the horn shark, Heterodontus francisci. MS thesis, University of South Florida.

Reilly, S. M. and Lauder, G. V. (1989). Physiological basis of feeding behavior in salamanders: do motor patterns vary with prey type? J. Exp. Biol. 141, 343-358.

Rountree, R. A. and Able, K. W. (1996). Seasonal abundance, growth and foraging habits of juvenile smooth dogfish, Mustelus canis, in a New Jersey estuary. Fish. Bull. 94, 522-534.

Russell, B. C. (1983). The food and feeding habits of rock reef fish of north-eastern New Zealand. N. Z. J. Mar. Freshwater Res. 17, 121-145.

Russo, R. A. (1975). Observations on the food habits of leopard sharks (Triakis semifasciata) and brown smoothhounds (Mustelus henlei). Calif. Fish Game, 61, 95-103.

Sedberry, G. R. (1987). Feeding habits of sheepshead, Archosargus probatocephalus, in offshore reef habitats of the southeastern continental shelf. Northeast Gulf Sci. 9, 29-37.

Sedberry, G. R. (1989). Feeding habits of the whitebone porgy, Calamus leucosteus (Teleostei: Sparidae), associated with hard bottom reefs off the southeaster United States. Fish. Bull. 87, 935-944.

Segura-Zarzosa, J. C. (1997). Observations on the feeding habits of the shark Heterodontus francisci Girard 1985 (Chondrichthyes: Heterodontidae), in San Francisco lagoon, Baja California Sur, Mexico. Ciencias Marinas 23, 111-128.

Shirai, S. (1996). Phylogenetic interrelationships of neoselachians (Chondrichthyes: Euselachii). In Interrelationships of Fishes (ed. M. Stiassney, L. Parenti and D. Johnson), pp. 9-34. San Diego: Academic Press.

Smith, B. G. (1942). The heterodontid sharks: Their natural history and the external development of Heterodontus japonicus based on notes and drawings by Bashford Dean. The Bashford Dean 


\section{C. D. Wilga And P. J. MotTA}

Memorial Volume: Archaic Fishes. Am. Mus. Nat. Hist. 8, 649-770.

Stevens, J. D. and Lyle, J. M. (1989). Biology of three hammerhead sharks (Eusphyrna blochii, Sphyrna mokarron and S. lewini). Aust. J. Mar. Freshwater Res. 40, 129-146.

Strong, W. R., Jr, Snelson, F. F. and Gruber, S. H. (1990). Hammerhead shark predation on stingrays: an observation of prey handling by Sphyrna mokarran. Copeia 1990, 836-840.

Summers, A. P. (2000). Stiffening the stingray skeleton - an investigation of durophagy in myliobatid stingrays (Chondrichthyes, Batoidea, Myliobatidae). J. Morph. 243, 113-126.

Talent, L. G. (1982). Food habits of the gray smoothhound, Mustelus californicus, the brown smoothhound, Mustelus henlei, the shovelnose guitarfish, Rhinobatos productus and the bat ray, Myliobatis californica, in Elkhorn slough, California. Cal. Fish Game 68, 224-234.

Tricas, T. C. (1997). Sharks. In Sharks and Rays (ed. T. C. Tricas, D. Deacon, P. Last, J. E. McCosker, T. I. Walker and L. Taylor), pp. 90-113. Australia: The Nature Company Guides.

Turingan, R. G. (1994). Ecomorphological relationships among Caribbean tetraodontiform fishes. J. Zool., Lond. 233, 493-521.

Turingan, R. G. and Wainwright, P. C. (1993). Morphological and functional bases of durophagy in the queen triggerfish, Balistes vetula (Pisces: Tetraodontiformes). J. Morph. 215, 101-118.
Vandewalle, P., Saintain, P. and Chardon, M. (1995). Structure and movements of the buccal and pharyngeal jaws in relation to feeding in Diplodus sargus. J. Fish Biol. 46, 623-956.

Wainwright, P. C. (1987). Biomechanical limits to ecological performance: mollusc-crushing by the Caribbean hogfish, Lachnolaimus maximus (Labridae). J. Zool., Lond. 213, 283-297.

Wainwright, P. C. (1988). Morphology and ecology: functional basis of feeding constraints in Caribbean labrid fishes. Ecology 69, 635-645.

Wainwright, P. C. and Turingan, R. G. (1993). Coupled versus uncoupled functional systems: motor plasticity in the queen triggerfish, Balistes vetula (Teleostei, Balistidae). J. Exp. Biol. 180, 209-227.

Wetherbee, B. M., Gruber, S. H. and Cortes, E. (1990). Diet, feeding habits, digestion and consumption in sharks, with special reference to the lemon shark, Negaprion brevirostris. In Elasmobranchs as Living Resources: Advances in the Biology, Ecology, Systematics and the Status of the Fisheries (ed. H. L. Pratt, Jr, S. H. Gruber and T. Taniuchi). NOAA Tech. Rep. 90. 29-47.

Wilga, C. D. and Motta, P. J. (1998a). Conservation and variation in the feeding mechanism of the spiny dogfish Squalus acanthias. J. Exp. Biol. 201, 1345-1358.

Wilga, C. D. and Motta, P. J. (1998b). The feeding mechanism of the Atlantic guitarfish Rhinobatos lentiginosus: modulation of kinematic and motor activity. J. Exp. Biol. 201, 3167-3184. 